Review

\title{
Seed Biofortification and Phytic Acid Reduction: A Conflict of Interest for the Plant?
}

\section{Francesca Sparvoli * and Eleonora Cominelli}

Institute of Agricultural Biology and Biotechnology, CNR, Via Bassini 15, 20133 Milan, Italy; E-Mail: cominelli@ibba.cnr.it

* Author to whom correspondence should be addressed; E-Mail: sparvoli@ibba.cnr.it; Tel.: +39-02-23699435; Fax: +39-02-23699411.

Academic Editor: Rishi R. Burlakoti

Received: 3 August 2015 / Accepted: 13 November 2015 / Published: 20 November 2015

\begin{abstract}
Most of the phosphorus in seeds is accumulated in the form of phytic acid (myo-inositol-1,2,3,4,5,6-hexakisphosphate, InsP6). This molecule is a strong chelator of cations important for nutrition, such as iron, zinc, magnesium, and calcium. For this reason, $\mathrm{InsP}_{6}$ is considered an antinutritional factor. In recent years, efforts to biofortify seeds through the generation of low phytic acid (lpa) mutants have been noteworthy. Moreover, genes involved in the biosynthesis and accumulation of this molecule have been isolated and characterized in different species. Beyond its role in phosphorus storage, phytic acid is a very important signaling molecule involved in different regulatory processes during plant development and responses to different stimuli. Consequently, many lpa mutants show different negative pleitotropic effects. The strength of these pleiotropic effects depends on the specific mutated gene, possible functional redundancy, the nature of the mutation, and the spatio-temporal expression of the gene. Breeding programs or transgenic approaches aimed at development of new lpa mutants must take into consideration these different aspects in order to maximize the utility of these mutants.
\end{abstract}

Keywords: gene regulation; inositol phosphates; mineral deficiency; phytate; signal transduction 


\section{Introduction}

Phytic acid (myo-inositol-1,2,3,4,5,6-hexakisphosphate, $\mathrm{InsP}_{6}$ ) is a ubiquitous component of eukaryotic cells which, together with its metabolism, plays a number of regulatory roles [1]. In plants, phytic acid is the most abundant form of phosphorus occurring in seeds (up to $85 \%$ of total phosphorus and with amounts even 1000 fold higher than those detected in vegetative tissues) and other plant tissues and organs such as pollen, roots, tubers and turions. During seed development, the synthesis of phytic acid is coordinated with that of other seed storage compounds. Accumulation significantly increases after the "cell division phase", reaching a plateau at the end of the "cell expansion phase" [2,3]. In mature seeds, phytate is organized into spherical inclusions called globoids, which are in turn found within protein bodies. Phytate deposits are also observed to occur transiently in various tissues and subcellular compartments during grain development [4-7]. Depending upon the species, the amount and distribution of phytic acid in different parts of the seed can be quite variable, with the most striking differences found in cereal grains. In the case of barley, wheat and rice, a large amount (80\%) of phytic acid is stored in the aleurone and bran (maternal teguments) and only a limited amount accumulates in the embryo. The distribution of phytate is opposite in maize seeds, where $80 \%$ of phytate accumulates in the embryo and scutellum [8]. In the case of legume seeds, such as common bean, more than $95 \%$ of seed phytic acid is accumulated in the cotyledons [9], while in the model species Arabidopsis, phytic acid is mostly stored in the embryo [5]. During germination, in order to support seedling growth, phytic acid is then degraded by phytase enzymes to remobilize the phosphorus stored as phytate salts [10].

Due to its chemical structure (highly negatively charged at physiological $\mathrm{pH}$ ), phytic acid easily precipitates in the form of phytate salts, binding important mineral cations such as iron, zinc, potassium, calcium, and magnesium. Monogastric animals, including humans, lack phytases in their digestive tract and fail to process the phytates present in seeds, thus phytic acid is poorly digested and decreases the nutritional value of the seeds by limiting phosphorus and mineral bioavailability. Poor mineral bioavailability, due to high molar ratios between phytic acid and mineral cations, is ascribed as one of the most important causes of mineral deficiencies (mainly iron and zinc) in populations whose diet is largely based on staple crops $[11,12]$. On the other hand, $\operatorname{Ins}_{6}$ is largely excreted by nonruminants. A common practice to provide for an animal's nutritional requirement for phosphorus $(\mathrm{P})$ has been the supplementation of feed with nutrient $\mathrm{P}$. However, this procedure increases $\mathrm{P}$ concentration in manure, leading to $\mathrm{P}$ accumulation in soils, and the consequent risk of $\mathrm{P}$ pollution in runoff water [13]. To obviate these problems, a solution is the development of low phytic acid (lpa) crop seeds [14].

The availability and management of $\mathrm{P}$ in agriculture is a challenging global problem: reserves of rock $\mathrm{P}$ are non-renewable and enhanced uptake and utilization of $\mathrm{P}$ would be of value for agricultural production in P-deficient environments throughout the world. It would also contribute to the long-term goal of sustainable and environmentally friendly agricultural production $[14,15]$. The total $\mathrm{P}$ accumulated in seed crops of major grains and legumes represents in sum more than $50 \%$ of the total $\mathrm{P}$ fertilizer used annually worldwide [16]. Therefore, reducing seed total $\mathrm{P}$, together with a reduction of phytate content, might also contribute to these goals [17]. This has been achieved at least for the barley lpa1-1 mutant, in which seeds show a decrease both in phytic acid and total P [18].

The biological functions of phytic acid and the identification of genetic resources and strategies useful in engineering high-yielding, stress-tolerant low-phytate germplasm have been reviewed by a number 
of authors $[10,11,14,17]$. However, in most cases, a strong emphasis was placed on the agronomic aspects of the topic, with only modest efforts to integrate these aspects with the emerging knowledge of the regulatory role of phytic acid and inositol metabolism. The aim of this review is to summarize the most recent results in the literature about relevant aspects of the phytic acid pathway and lpa mutants. Moreover, we discuss some pleiotropic effects of lpa mutants with respect to the reported roles, important for cell signaling and plant processes, of phytic acid and key enzymes and metabolites of this complex pathway.

\section{Biosynthetic Pathways}

In plants, it is now generally accepted that $\mathrm{InsP}_{6}$ biosynthesis occurs through two different routes: a "lipid-dependent" pathway, which is ubiquitous in eukaryotic cells, and a "lipid-independent" pathway (Figure 1). The first operates in all plant tissues, while the second appears to predominanate in seeds. Phytic acid biosynthesis needs the de novo production of myo-inositol (hereafter referred to as "Ins") through a highly conserved reaction, shared by all living organisms, in which the enzyme D-myo-inositol 3-phosphate synthase (MIPS) converts D-glucose-6-phosphate to myo-inositol 3-phosphate $\left(\operatorname{Ins}(3) \mathrm{P}_{1}\right)$ (Figure 1). Myo-inositol 3-phosphate is then dephosphorylated to free Ins by a specific $\mathrm{Mg}^{2+}$-dependent inositol monophosphate phosphatase (IMP). Interestingly, the IMP enzyme has a dual activity: besides Ins(3) $\mathrm{P}_{1}$, it also hydrolyzes L-galactose 1-phosphate (L-Gal 1-P), a precursor of ascorbic acid synthesis $[19,20]$. The reaction catalyzed by IMP can be reversed by the action of myo-inositol kinase (MIK). Since Ins(3)P1 is produced directly from glucose 6-phosphate by MIPS, it is not clear exactly why MIK activity is important for $\mathrm{InsP}_{6}$ biosynthesis, although the importance of MIK in seed $\operatorname{InsP}_{6}$ metabolism has been demonstrated by a number of mutations in the MIK gene [21-23]. A possible explanation is that MIK could provide more substrate diversity for the generation of inositol bisphosphate to feed the lipid-independent pathway, since it is able to produce multiple inositol monophosphates [21].

The main difference between the "lipid-dependent" and "lipid-independent" routes is the way inositol tri-phosphates $\left(\mathrm{InsP}_{3}\right)$ are generated. In the "lipid-dependent" pathway, Ins is converted to phosphatidylinositol (PtdIns) by a phosphatidylinositol synthase (PtdIS). Next, the headgroup of PtdIns is sequentially phosphorylated by phosphatidylinositol kinases to produce $\operatorname{PtdIns}(4,5) \mathrm{P}_{2}$. This molecule is the substrate of a PtdIns-specific phospholipase $C$ activity that releases $\operatorname{Ins}(1,4,5) \mathrm{P}_{3}$, a molecule central to signal transduction [24].

The so-called "lipid-independent" pathway is entirely independent from inositol lipid synthesis and consists of sequential phosphorylation of the Ins ring to $\mathrm{InsP}_{6}$, through the action of a number of specific inositol phosphate kinases. As already mentioned, the first phosphorylation step, consisting in the conversion of Ins to $\mathrm{InsP}_{1}$, is catalyzed by myo-inositol kinase (MIK). The production of InsP from InsP $\mathrm{P}_{1}$ requires a monophosphate kinase. A good candidate for this step is a homolog of 2-phosphoglycerate kinase (2-PGK), which catalyzes the production of 2,3-6 bisphosphoglycerate from 2-phosphoglycerate in archaea [14]. In rice, a mutation in this gene (OsPGK1) generates an lpa phenotype, while overexpression increases seed $\mathrm{InsP}_{6}$ content, suggesting that $O s P G K 1$ is a key gene for $\operatorname{InsP}_{6}$ synthesis, being involved in (probably the rate-limiting) step from $\operatorname{InsP}_{1}$ to $\operatorname{Ins}_{2}[22,25,26]$. Further phosphorylation steps, required to convert $\mathrm{InsP}_{3}$ into the more phosphorylated $\mathrm{InsP}_{4}, \operatorname{InsP}_{5}$ and $\operatorname{InsP}_{6}$, involve at least three types of inositol kinases: (i) the evolutionarily conserved inositol phosphate kinase 2 , 
also known as inositol polyphosphate multikinase (IPK2/IPMK), which is a dual 6-/3-kinase; (ii) the inositol 1,3,4-trisphosphate 5-/6-kinase (ITPK) belonging to the family of ATP-grasp fold proteins; and (iii) the inositol polyphosphate 2-kinase (IPK1), which specifically phosphorylates InsPs in the 2-position.

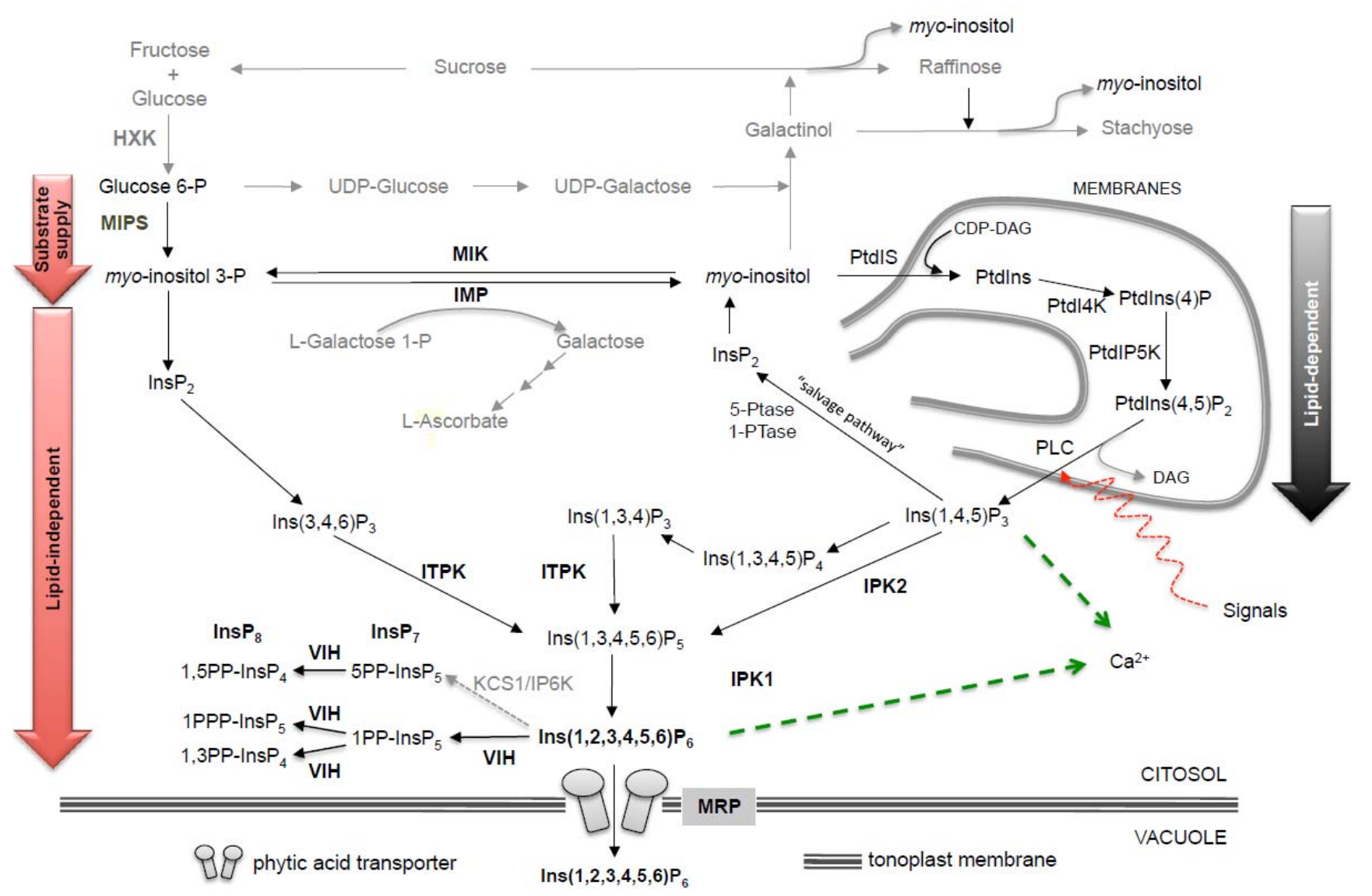

Figure 1. Schematic representation of phytic acid biosynthetic pathway (black) and myo-inositol derived pathways for ascorbic acid and raffinose-type oligosaccharides (grey). The substrate supply, lipid independent (red) and lipid dependent (dark grey) sub-pathways for myoinositol-1,2,3,4,5,6-hexakisphosphate ( $\mathrm{InsP}_{6}$ ) synthesis are indicated. MIPS, myo-inositol-3phosphate synthase; IMP, bifunctional enzyme: myo-inositol-phosphate monophosphatase and galactose-1-phosphate phosphatase; MIOX, myo-inositol monooxygenase; MIK, myoinositol kinase; IPK2, inositol 1,4,5-tris-phosphate kinase; ITPK, inositol 1,3,4-triphosphate 5/6-kinase; IPK1, inositol 1,3,4,5,6 pentakisphosphate 2-kinase; PtdIS, phosphatidyl inositol phosphate synthase; PtdI4K, phosphatidyl inositol 4-kinase; PtdIP5K, phosphatidyl inositol 4-phospate 5-kinase; PtdIns,phosphatidyl inositol; PtdInsP1, phosphatidyl inositol monophosphate; PtdInsP2, phosphatidyl inositol biphosphate; PLC, phospholipase C; MRP, multidrug-resistance-associated protein ATP-binding cassette; HXK, hexokinase; VIH, diphosphoinositol pentakisphosphate kinase; KCS1, inositol hexakisphosphate kinase. Dotted grey line indicates a second route for $\mathrm{InsP}_{7}$ synthesis, existing in eukaryotes but not found in plants. 
Once synthesized, phytic acid is stored as globoids inside the storage vacuoles where it is actively transported by a specific InsP 6 transporter, a multidrug-resistance-associated protein (MRP), belonging to the ATP-binding cassette (ABC) family [27]. The involvement of all the above-mentioned proteins in $\mathrm{InsP}_{6}$ synthesis and accumulation is supported by direct enzyme isolation and biochemical characterization and/or by the isolation of corresponding lpa mutants [19,28-34] (Table S1).

\subsection{Genomic Organization and Regulation of Phytic Acid Pathway Genes}

Genes involved in phytic acid biosynthesis and transport have been characterized in Arabidopsis thaliana and crop plants such as rice, wheat, soybean and common bean, through forward (through the screening for Ipa mutations) and reverse genetics [35-39]. In this section we will describe the main classes of genes coding for enzymes of the pathway, MIPS, IMP, MIK, 2-PGK, IPK2, ITK and IPK1, and MRP genes coding for $\mathrm{InsP}_{6}$ transporters. Most of these are members of small gene families, with the exception of $M I K$, which is typically encoded by a single copy locus [35]. However, some differences among species have been reported concerning the presence of single or multiple loci for each gene function. Moreover, the tissue specificity of expression can vary among members of a gene family, and may indicate redundancy in vegetative or seed tissues. All these aspects contribute significantly to the establishment of possible lpa mutant phenotypes.

\subsubsection{MIPS}

The MIPS gene is a prime example of variable loci numbers reported across species. In fact, in the barley genome, the presence of only one MIPS gene has been described, while two are present in rice and common bean, and several are found in Arabidopsis, maize, and soybean [36,37,40-44]. One of two MIPS genes in rice and in common bean, and one of four in soybean were highly expressed in developing seeds $[36,37,40]$ and their down-regulation in rice and soybean, through mutation or RNAi, caused an lpa phenotype in seeds [43,45-47]. However, a systematic study performed on mutants isolated in Arabidopsis showed that no single mutant in three MIPS genes induces an lpa phenotype in seeds, suggesting a redundant role for these genes [35]. Interestingly, a reduction in $\mathrm{InsP}_{6}$ in leaves was reported for atmips1 and atmips2 mutant plants. Moreover, atmips2 showed increased susceptibility to viruses, fungi and bacteria, while atips1 did not, suggesting a different degree of redundancy between the two genes in vegetative versus seed tissues [48]. Promoter-GUS fusion analyses of the three Arabidopsis genes showed overlapping activity of AtMIPS1, AtMIPS2 and AtMIPS3 promoters at the globular stage of seed development [44]. At later stages, strong GUS staining was present in the entire seed only for AtMIPS1, while AtMIPS2 and AtMIPS3 promoter activity was limited to the seed coat and funiculus [44]. These data suggest an essential role of myo-inositol synthesis at early stages of embryo development, but not at later stages, when the synthesis of myo-inositol mediated by AtMIPS1 alone seems to be sufficient. However, as the complete knock out of AtMIPS1 caused neither an lpa phenotype in the seed [35] nor embryo abnormalities, under normal (non stressed) conditions as observed in double and triple mutant (embryo lethality in this last case) [44], it can be deduced that the myo-inositol synthesized in the endosperm and maternal tissues by AtMIPS2 and AtMIPS3 can be transported into the embryo [44]. Immunolocalization studies, with an antibody against the three AtMIPS isoforms, showed that AtMIPS proteins appear to be specifically located within the endosperm cytosol both at torpedo stage and in mature 
seed, but not in the embryo, where phytic acid is accumulated [49]. These data on protein localization do not exactly correlate with the expression of AtMIPS1 [44], suggesting that a post-trascriptional regulation of AtMIPS expression is present in the seed. Moreover, the presence of AtMIPS proteins in the endosperm, a seed compartment where $\mathrm{InsP}_{6}$ is not accumulated, implies a complex interaction between endosperm and embryo during the synthesis and subsequent accumulation of InsP $\mathrm{P}_{6}$ during Arabidopsis seed development [49]. In contrast, RINO1 (the rice seed MIPS gene) transcript was first detected at the apex of embryos of developing rice seeds [42]. Consequently, its expression colocalizes with InsP6-containing globoids within the scutellum and aleurone layers [4]. In soybean, GmMIPS1 expression was first detected in maternal tissue, and then in the embryo and cotyledons [50]. In both monocots and dicots, MIPS expression starts very early during seed development, a few days before the beginning of accumulation of phytic acid, and then decreases [36,37].

\subsubsection{Myo-Inositol Reversible Dephosphsorylation: IMP and MIK}

IMP genes form a small family including IMP genes, similar to mammalian ones, and IMPL (IMP-like) genes, coding for chloroplastic proteins more similar to prokaryotic IMP genes [19,36]. A different number of loci coding for IMP enzymes has been reported in different species: one IMP gene in barley and in common bean [37,51], one IMP and one IMPL gene in rice [36], one IMP and two IMPL genes in Arabidopsis [19], and three IMP genes in tomato [52]. The three Arabidopsis genes are expressed in several tissues with AtIMP showing the highest levels of expression, except in seeds, where AtIMPL1 is predominant [53]. Interestingly, a time course analysis of seed development showed IMP and IMPL gene expression correlated with that of SAL1/FRY, which codes for myo-inositol polyphosphate 1-phosphatase. This enzyme is involved in the myo-inositol "salvage pathway" and SAL1/FRY expression only partially overlaps the expression of AtMIPS genes. This expression pattern suggested that the salvage pathway may also be involved in myo-inositol synthesis during seed development [54]. More recently, it was shown that AtIMPL2 functions in the histidine biosynthetic pathway while AtIMP and AtIMPL1 catalyze the hydrolysis of inositol- and galactose-phosphates in Arabidopsis vegetative tissues [53]. During common bean seed development, PvIMP expression is similar to that of MIPS, being very high at early stages, and then declining to undetectable levels before the start of phytic acid accumulation [37].

To date, one $M I K$ gene has been identified in plant genomes [21,23,35,37]. This gene is expressed at high levels during seed development, as shown in Arabidopsis and common bean [35,37].

\subsubsection{PGK}

Genes coding for 2-PGK have been characterized only in rice and Arabidopsis [22,25,26]. In rice, OsLpa1 (OsPGK1) is expressed in shoot, root, and panicle [23]. In Arabidopsis, two genes of this family were described, At5g60760 and At3g45090. They are present in different organs, however only At5g60760 is highly expressed during silique development and is ncessary for $\mathrm{InsP}_{6}$ synthesis [22]. Among the different Arabidopsis genes involved in phytic acid synthesis in siliques, At5g60760 together with AtMIK is the most highly expressed [35]. 


\subsubsection{IPK2}

IPK2 kinase is specific for the lipid-dependent pathway, which is not the major route to phytic acid in the seed [14]. However, a low phytate seed phenotype (reduction of phytic acid content by $35 \%-48 \%$ ) in the Arabidopsis atipk2 $\beta$ mutant indicates the lipid-dependent pathway is active in the seed [55]. Despite similar expression in vegetative and reproductive tissues, mutation of AtIPK2 $\alpha$ has no effect on levels of phytic acid in the seed, suggesting independent roles for the two genes in seed development [35]. AtIPK2 $\alpha$ plays also a role in pollen germination and root growth [56], while AtIPK2 $\beta$ is involved in axillary shoot branching through the auxin signaling pathway [57] and its expression in tobacco leads to improved tolerance to abiotic stresses [58]. Consistent with the role of IPK2 in later steps of phytic acid synthesis, IPK2 transcripts, when assessed during seed development, showed the highest accumulation later than MIPS and IMP.

\subsubsection{ITPK}

ITPK proteins cluster into three phylogenetic subgroups: $\alpha, \beta$ and $\gamma[34,36,39]$. Six different ITPKs have been described in rice [36], four in Arabidopsis [32,59,60], soybean [39] and wheat [38], at least three in common bean [37] and one in maize [61,62]. Among the six rice ITPKs genes, OsITP5/6K-4 ( $\alpha$ subgroup) and OsITP5/6K-6 $(\gamma)$, showed seed-specific expression, with OsITP5/6K-4 transcript being particularly abundant in the aleurone and OsITP5/6K-6 in the embryo [36]. For OsITP5/6K-6 (Os09g34300), a knock out mutant with lpa phenotype was recently described [63]. In Arabidopsis, the AtITPK1 belongs to the $\alpha$ subgroup, AtITPK2 and AtITPK3 to the $\beta$ and AtITPK4 to the $\gamma$. AtITPK genes are expressed in different tissues, with none specifically expressed in siliques [32,64]. AtITPK1 and AtITPK4 lpa mutants have been isolated, indicating that these two genes are not redundant [35]. An explanation for their non-redundant function is that AtITPK4 lacks inositol 3,4,5,6-tetrakisphosphate 1-kinase activity, characteristic of other AtITPKs, but instead shows inositol 1,4,5,6-tetrakisphosphate and inositol 1,3,4,5-tetrakisphosphate isomerase activity [32]. Soybean GmITPK3, showed higher expression in early stages of seed development compared to the other GmITPKs [39], and belongs to the $\beta$ subgroup. The ITPK maize gene, ZmIPK ( $\alpha$ subgroup), showed embryo-specific expression, and the mutation affecting this gene causes an lpa phenotype [62]. ITPK genes are generally expressed at similar levels during seed development with a decrease in expression at later phases for some members of the family [36-38].

\subsubsection{IPK1}

A single IPK1 gene was described in several crop plants. The rice OsIPK1 shows the highest expression in the aleurone between 7 and 10 days after anthesis [36]; common bean PvIPK1 expression does not appear to be significantly regulated during seed development [37]; and wheat TaIPK1 doubles its expression during seed development [38]. Two IPK1 genes were described in maize and in Arabidopsis. The maize ZmIPK1A gene is expressed in a range of tissues including immature ears, seeds at 12 DAF, middle-stage endosperm and maturing embryos, while ZmIPK1B is expressed in roots [33]; the two Arabidopsis IPK1 genes are expressed in different tissues, with only one expressed in siliques that 
causes an $83 \%$ reduction in seed phytate level when knocked down $[31,55]$. Three IPK1 genes were identified in soybean and only one is highly expressed in the seed [65].

\subsubsection{MRP}

The first gene coding for an ABCC-type InsP $_{6}$ transporter was mapped to the maize ZmMRP4 locus [66]. The functional characterization of this gene family was performed with the Arabidopsis homolog AtMRP5 (also referred to as AtABCC5) [67], previously characterized for its involvement in regulating stomatal movements and drought tolerance [68,69]. Phylogenetic analyses of MRP type transporters indicate that InsP $\mathrm{P}_{6}$ transporters are represented as single copy genes [70-72], as described for Arabidopsis AtMRP5, maize ZmMRP4 and rice OsMRP5 [66,67,73]. ZmMRP4 and OsMRP5 are expressed in different organs including seeds [66,73]. AtMRP5-promoter fusion to a GUS reporter gene showed staining mainly in vascular tissues and in guard cells, with no staining in seeds [74]. However, from publicly available microarray data, it is clear that AtMRP5 is expressed at different stages of seed development [75]. It has been recently shown that soybean and common bean, two closely related legume species, bear a paralog copy (PvMRP2 and GmMRP13) of the genes characterized for their role in phytic acid accumulation (PvMRP1 and GmMRP3 and GmMRP19) [76,77]. In common bean PvMRP1 and $P v M R P 2$ are expressed in almost all tissues at similar levels, with the exception of developing seeds, where $P v M R P 1$ is expressed at consistently higher levels than PvMRP2 (unpublished resultsA similar behavior is found for the corresponding soybean genes [78].

\section{Low Phytic Acid (lpa) Mutants}

Several lpa mutants have been isolated in important grain crops, such as barley, maize, rice, wheat, soybean, common bean and pea (Table S1). Ipa mutations can be grouped into three classes, depending on the affected step of the biosynthetic pathway or mode of compartmentation/transport: (i) mutations involved the first steps of the pathway (from glucose 6-P to myo-inositol 3-phosphate), commonly indicated as "supply pathway"; (ii) mutations perturbing the end of the pathway (from myo-inositol 3-phosphate to $\mathrm{InsP}_{6}$ ); and (iii) mutations affecting tissue compartmentation of $\mathrm{InsP}_{6}$ and/or its transport and storage to the vacuole (MRP transporter) (Figure 1). Mutants belonging to the first and the third classes are generally characterized by decreased $\mathrm{InsP}_{6}$ levels accompanied by a molar equivalent increase in inorganic $\mathrm{P}_{\mathrm{i}}$, but not by accumulation of lower Ins $\mathrm{P}_{\mathrm{s}}$ (inositol phosphates with up to five phosphate residues), a characteristic specific of the second class of mutants (Table 1).

The similarities between the first and third class of mutants triggered some confusion in the initial characterization of some lpa mutants in the $\mathrm{InsP}_{6}$ transporter genes $(M R P)$. The first hypothesis was that they were affected in the MIPS gene [61,79]. In fact, a reduced expression of the ZmMIPS1S gene was reported in the maize lpa1 mutant. However, mapping of the maize lpa1 locus led to the identification of a defective ZmMRP4 [66]. Available maize genomic data helped to identify that the ZmMIPS1S and the ZmMRP4 genes map very closely on chromosome 1S, thus explaining the incorrect association of the mutation to the ZmMIPS1S gene $[61,66,79,80]$. Phylogenetic studies identified the AtABCC5/AtMRP5, a high affinity InsP 6 ATP-binding cassette transporter, as the closest Arabidopsis homologue of ZmMRP4 [67]. Later, Ipa mutations already isolated in rice, soybean and common bean [81-83] were shown to affect genes orthologous to ZmMRP4/AtMRP5 [73,76,77,84,85]. 
Table 1. Classification of lpa mutations on the basis of the affected function in the pathway for phytic acid synthesis and accumulation.

\begin{tabular}{|c|c|c|}
\hline Class & Gene Function & Effects on the Pathway \\
\hline Type 1 & $\begin{array}{l}\text { MIPS } \\
\text { MIK } \\
\text { IMP }\end{array}$ & $\begin{array}{l}\text { Decrease in phytic acid accompanied by } \\
\text { a molar increase in free phosphate }\end{array}$ \\
\hline Type 2 & $\begin{array}{l}\text { 2PGK } \\
\text { IPK2 } \\
\text { ITPK } \\
\text { IPK1 } \\
\end{array}$ & $\begin{array}{l}\text { Decrease in phytic acid accompanied by a } \\
\text { low increase in free phosphate and increased } \\
\text { content of lower inositol phosphates (InsPs) }\end{array}$ \\
\hline Type 3 & $\begin{array}{l}\text { MRP } \\
\text { Putative sulfate transporter } \\
\text { (sultr3;3) }\end{array}$ & $\begin{array}{l}\text { Decrease in phytic acid accompanied by } \\
\text { a molar increase in free phosphate and/or } \\
\text { decrease in phytic acid in specific seed tissues }\end{array}$ \\
\hline
\end{tabular}

\section{Metabolic and Phenotypic Traits of Low Phytic Acid Mutants}

To ensure mineral bioavailabity, the reduction of the phytate:mineral cation molar ratio is very important, thus a consistent phytic acid reduction is highly desirable in lpa mutants. Unfortunately, negative agronomic traits, such as low germination rates, reduced seed development and weight, and stunted vegetative growth, have been frequently reported for many lpa mutants, making them of limited value to breeders [61,86-89]. For many crops, obtaining lpa mutants with no or very limited pleiotropic agronomic defects still remains a challenging goal, although a few well performing lpa mutants have been reported [90-92]. In barley, at least one lpa mutant (Hvlpa1-1) has been shown to be equivalent to or even better than its wild type parent. In addition, some lpa mutations do not severely affect the yields, especially in non-stressful production environments, thus suggesting that at least some lpa mutants show potential for use in breeding [90,93] and a number of lpa varieties have been registered [94,95].

The number and strength of pleiotropic effects on $\mathrm{InsP}_{6}$ biosynthesis in lpa mutants are the result of differences in copy number (functional redundancy) and the spatio-temporal expression of genes and their respective products (protein and metabolite localization). In addition, an increasing number of studies describe tight integration of $\mathrm{InsP}_{6}$ metabolic and signaling pathways. The existence of complex metabolic crosstalk among enzyme activities and the type and abundance of different InsPs in a differentiated cell types and tissues may result in unexpected phenotypes (reviewed by [96-100]).

The most severe pleiotropic defects have been found in lpa mutants carrying defective MIPS or MRP genes, as well as in mutants in other genes that result in phytic acid reductions of more than $70 \%$ (Table S1 and references therein). These negative effects on agronomic performance and seed viability are not surprising, given that most of the lpa mutations affect myo-inositol and other metabolites that are important for normal development. Since MIPS activity is the only source of the myo-inositol ring, and since myo-inositol is an essential cellular metabolite important to numerous pathways and functions (Figure 2), perturbing MIPS expression may prove deleterious, if not lethal, even if MIPS suppression is specifically targeted to the seed. For example, mips soybean mutants (L33 and Gm-lpa-TW75-1), with $50 \%$ phytic acid decrease, showed reduced field emergence, especially when seeds were produced in a subtropical environment (the so-called "seed-source" effect), while high seed abortion and 95\% phytic 
acid reduction occur in transgenic soybean plants with an almost complete suppression of the MIPS gene by RNAi [45,86,101]. Defects in embryogenesis and embryo lethality have been reported for Arabidopsis mips mutants [102,103]. Maize and rice lpa mutants, with defects in the MRP gene, have very similar phenotypes, and the severity of the phenotype (seedling or embryo death) correlates with the extent of phytic acid reductions [61,73,88,104,105]. Surprisingly, no embryo defects neither seed lethality/abortion have been reported for known mrp mutants of dicot species (soybean, common bean and Arabidopsis), although phytic acid is significantly reduced in their seeds $[67,82,85]$. Most likely, tissue and cellular compartmentation of the phytic acid pathway significantly contributes to the effects on seed development caused by perturbations due to lpa mutations $[14,50]$.

Altered myo-inositol contents have been reported in many lpa mutants. As expected, mips and mik mutants have seed myo-inositol levels lower and higher than wild type, respectively (Table S1 and references therein). The soybean mutant Gm-Ipa-ZC-2, harboring a non-functional IPK1 protein, has increased myo-inositol levels [65]. Contrasting data are reported in mrp mutants of maize and common bean. In these mutants MIPS gene expression is downregulated, thus lower seed myo-inositol content would be expected. This occurs in the bean Ipa1 and the maize lpa1-241 mutants, however higher seed myo-inositol has been reported in the maize lpa1-1 mutant [66,76,106]. An inverse relationship between MIPS expression and seed myo-inositol content is also observed in two allelic mrp mutations of rice and in three barley lpa mutants (lpa2-1, lpa3-3 and M955), for which the molecular defects are still unknown [81,107]. Changes in myo-inositol content also affect the synthesis of derived metabolites, such as galactinol and raffinosaccharides (Table S1) [43,76,107-110]. Seed myo-inositol content has also been suggested to correlate with response to ABA during seed germination [19,76,111]. The Arabidopsis and common bean lpa ( $\mathrm{mrp}$ ) mutants have opposite myo-inositol seed contents and also show opposite responses to ABA during germination, which is strongly inhibited in common bean lpa1 (Pvmrp1) mutant, while it is unaffected in the Arabidopsis mrp5 seeds $[68,76]$. Ins $(1,4,5) \mathrm{P}_{3}$ $\left(\mathrm{Ins}_{3}\right)$ levels are critical for $\mathrm{ABA}$ response in germinating seeds, as ABA hypersensitivity is accompanied by an increase in $\mathrm{InsP}_{3}$ catabolism [112-114]. Most likely, the flux of myo-inositol used to feed the lipid dependent pathway leading to the production of $\operatorname{Ins}(1,4,5) \mathrm{P}_{3}$ or the regulation of the salvage pathway used for myo-inositol catabolism might be affected in these mrp mutants (Figure 1).

Misregulation (in most cases downregulation) of multiple genes for the synthesis and transport/accumulation of phytic acid has also been reported in a number of lpa mutants. Decreased expression of MIPS and IMP has been shown in Ipa2-1, Ipa3-3 and M955 barley mutants [107]. A point mutation in the bean phytic acid transporter (Pvmrp1) causes a general transcriptional down regulation of the genes of phytic acid pathway, indicating that the myo-inositol cellular pool and phytic acid biosynthesis are controlled by phytic acid itself and/or other constituents of the pathway [76]. Similar results have been reported in a more extensive study on the Arabidopsis lpa mutants atmik, atitpk1, atitpk4, atipk1, atipk2 $\beta$, atmrp5 and at2pgk [35]. In these knock-out mutants, the expression of several genes of the InsP 6 pathway was affected, confirming that other constituents of InsP 6 metabolism also modulate the transcription of genes in the $\mathrm{InsP}_{6}$ pathway. Another interesting outcome of this study was the observation that the lipid dependent pathway, compared to the lipid independent one, has a more relevant regulatory role in mediating stress response. In fact, defects affecting inositol phosphate kinases (atipk1, atipk2ß, atitpk1 and atitpk4-1) are more relevant for abiotic stress ( $\mathrm{NaCl}$, mannitol and 
$\mathrm{H}_{2} \mathrm{O}_{2}$ ) sensitivity, than mutations in genes of the early pathway (atmik1 and at2pgk) or in the phytic acid transporter (atmrp5).

The pathway for phytic acid biosynthesis is more than a simple, linear addition of phosphate esters, and its complexity is well illustrated by the multiple activities of the inositol tris/tetra kisphosphate kinases (ITPKs). These enzymes have been shown to have multiple substrate specificity, and, in some cases, may also act as isomerases and/or phosphatases of several inositol phosphates [34,39,59]. ITPKs may differ in their tissue and time of expression, as well as their substrate specificity and affinity [32,34,36,37,39,59]. For example, rice and barley ITPKs (OsIpk and HvIpk) show the highest affinity for the $\operatorname{Ins}(3,4,5,6) \mathrm{P}_{4} \rightarrow \operatorname{Ins}(1,3,4,5,6) \mathrm{P}_{5}$ reaction, in agreement with the results obtained for the maize ITPK gene (ZmItpk) [62]. However, the OsItpk and HvItpk proteins also have high activity towards $\operatorname{Ins}(3,4,5) \mathrm{P}_{3}$ and are able to produce $\operatorname{Ins}(1,3,4,5,6) \mathrm{P}_{5}$ using an $\mathrm{InsP}_{4}$ as intermediate, but, contrary to ZmItpk, they are not capable of phosphorylating Ins $(1,3,4,5) \mathrm{P}_{4}$ [34].

\section{Enzymes and Metabolites of the Phytic Acid Pathway Have Regulatory Roles in Cell Signaling and Plant Processes}

Despite its importance, the biological role of $\mathrm{InsP}_{6}$ in plants is still poorly understood in both normal and extreme environmental conditions. Myo-inositol synthesis and catabolism impact metabolites involved in many critical plant biochemical pathways, such as (i) the production of compatible solutes, like galactinol, raffinose family oligosaccharides, pinitol and cell wall polysaccharides; (ii) the generation of inositol polyphosphates (InsPs), phytic acid and inositol polyphosphate pyrophosphates (PP-InsPs); and (iii) the synthesis of phosphoinositides and the production of $\operatorname{Ins}(1,4,5) \mathrm{P}_{3}$ (Figure 2). Furthermore, D-glucuronic acid, the primary breakdown product of Ins, is utilized in the synthesis of various cell wall pectic and noncellulosic compounds and ascorbic acid [115-117]. A growing body of data is elucidating the roles played by inositol metabolism in diverse plant developmental and physiological processes including signal transduction [113,118], sugar signaling [115], storage and polar transport of auxin [44,119], membrane trafficking [120], abiotic and biotic stress response [48,121], phosphorus homeostasis [55,122], photomorphogenesis [64], chromatin modification and remodeling [122,123], and mRNA nuclear export [124]. Highly phosphorylated inositols (InsP5, InsP 6 , InsP 7 , InsP8) have also been shown to serve as ligands of plant hormone receptors [125-127]. Moreover, several genes, enzymes and compounds for inositol phosphates and, eventually, phytic acid synthesis are part of cytosolic and nuclear metabolic pools with a central role in cellular metabolism. Thus, any perturbations of the pathway, such as those occurring in lpa mutants, may significantly impact seed and plant development (Figure 2). 


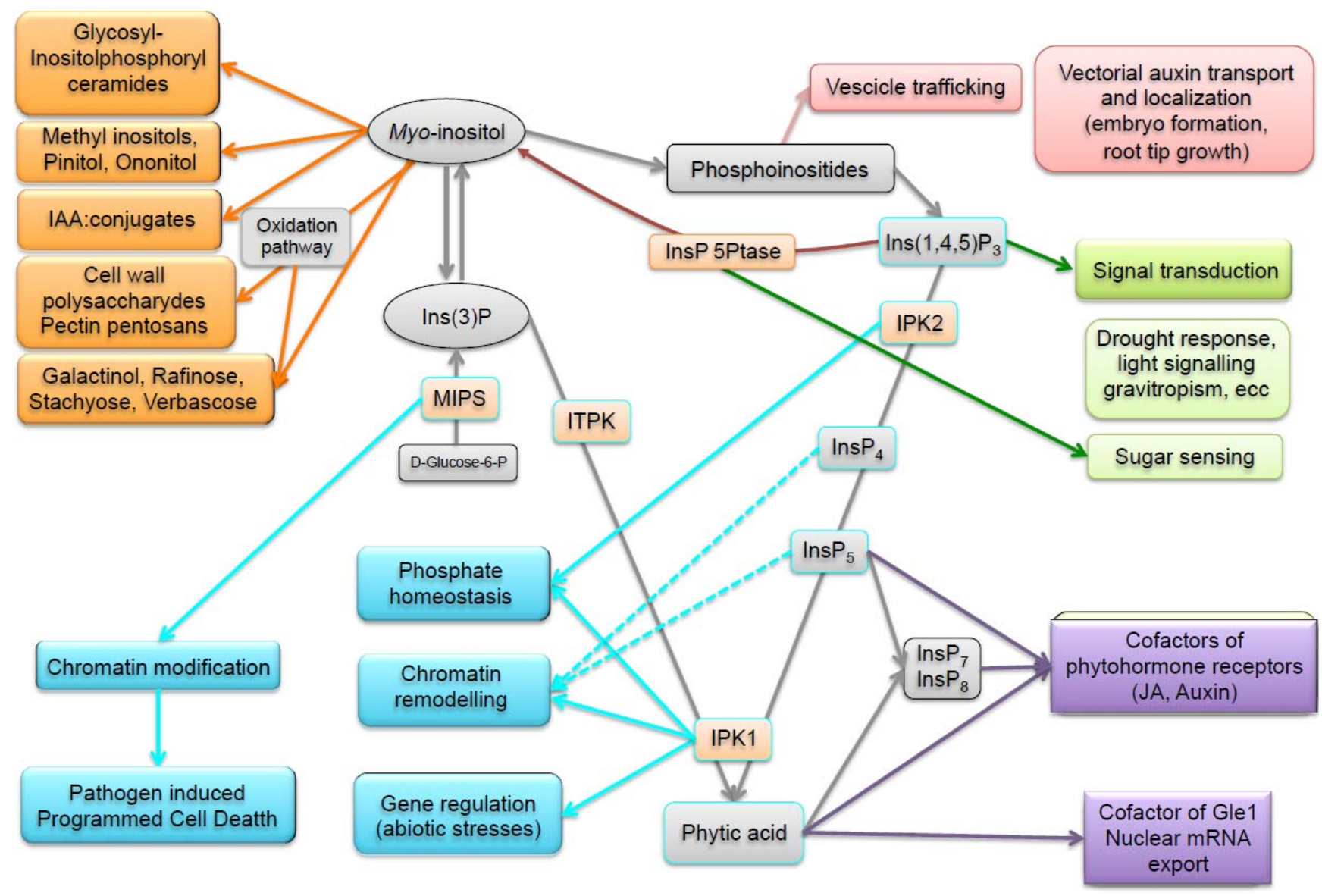

Figure 2. Scheme showing and summarizing the diverse roles of inositol metabolism and phytic acid pathway in compatible pathways (orange), signal transduction (green), membrane biogenesis and trafficking (red), gene regulation (light blue), and as cofactors of regulatory proteins (violet). Light blue boxed enzymes and metabolites have been found localized both in the nucleus and in the cytosol.

\subsection{Signal Transduction}

Inositol metabolism plays a significant role in a wide range of plant developmental and physiological processes, such as response to diverse stimuli (light, gravitropism, abiotic and biotic stresses), downstream responses to $\mathrm{ABA}$ and sugars, and auxin mediated processes, among others, as described below. Key molecules are the well known $\operatorname{Ins}(1,4,5) \mathrm{P}_{3}\left(\mathrm{InsP}_{3}\right)$ and $\mathrm{InsP}_{6}$. Very recently, inositol pyrophosphates ( $\mathrm{Ins}_{7}$ and $\mathrm{Ins}_{8}$ ) have been proposed as unique signaling molecules involved in energy sensing and metabolism [127-131]. These high energy molecules, containing a linear chain of two (PP) or three (PPP) phosphates linked to an InsP 6 molecule (Figure 1), have been implicated in determination of the phenotypes of lpa mutants, based on their increased expression in seeds of Arabidopsis and maize mrp mutants (mrp5 and lpa1-1 respectively) [129].

In eukaryotes, the myo-inositol signaling pathway relies on $\mathrm{InsP}_{3}$ as second messenger to trigger intracellular $\mathrm{Ca}^{2+}$ release from intracellular stores. When exposed to an external stimulus, the cell responds increasing $\mathrm{InsP}_{3}$, which is generated by the action of phospholipase $\mathrm{C}$ (PLC). The signal induced by $\mathrm{InsP}_{3}$ can be terminated through a catabolic pathway (the so-called "salvage pathway"), in which myo-inositol polyphosphate phosphatases (Ptases) remove the 5-phosphate to regenerate 
myo-inositol, or by $\mathrm{InsP}_{3}$ removal through sequential phosphorylation mediated by IPK2 (Figure 1). Thus, InsPs and PtdInsPs are interdependent compounds, as PtdInsPs are used as substrates by PLCs to produce InsPs, and InsPs breakdown produces myo-inositol used as substrate to produce PtdInsPs. The direct role of $\mathrm{InsP}_{3}$ in signaling is in question, as an emerging idea is that InsP $\mathrm{P}_{3}$ plays a role simply as a precursor of $\mathrm{InsP}_{6}$ [121]. In fact, in guard cells, InsP 6 has been shown to trigger intracellular $\mathrm{Ca}^{2+}$ release after $\mathrm{ABA}$ addition with an efficiency $\approx 100$ times higher than that of $\mathrm{InsP}_{3}$ [118]. Moreover, there is no evidence of a canonical $\mathrm{InsP}_{3}$ receptor in plants, although this holds true also for InsP $\mathrm{P}_{6}$ One possibility is that plants do not possess an InsP-regulated calcium channel, and an entirely different and uncharacterized mechanism allows both $\mathrm{InsP}_{3}$ and $\mathrm{InsP}_{6}$ to regulate $\mathrm{Ca}^{2+}$ release, either simultaneously, or independently [111]. Most likely, both $\mathrm{InsP}_{3}$ and $\mathrm{InsP}_{6}$ have parallel and overlapping functions in plants, and there is a large body of evidence showing that InsPs impact cellular $\mathrm{Ca}^{2+}$ levels. Undoubtedly a strong correlation exists between these two molecules as demonstrated by the finding that transgenic plants and plant cells that constitutively break down $\operatorname{InsP}_{3}$ or synthesize $\mathrm{PtdInsP}_{2}$ contain changes in InsP $\mathrm{P}_{6}$ : so changes in InsP $\mathrm{P}_{3}$ are mirrored by changes in $\operatorname{InsP}_{6}$ [132-134].

Rapid increases in $\mathrm{InsP}_{3}$ have been reported in response to myriad stimuli, such as gravitropism, light, salt stress, gibberellic acid, anoxia, cold, heat, drought, and exposure to plant pathogens and elicitors $[111,113,114]$. Thus, directly or indirectly, $\mathrm{InsP}_{3}$ is crucial to signal transduction. Intriguingly, conditions that lower $\mathrm{InsP}_{3}$ mediated signals, while revealing predictable phenotypes based on signal transduction paradigms, also showed unexpected phenotypes. For example, Arabidopsis plants overexpressing human type I inositol polyphosphate 5-phosphatase (InsP 5Ptase), have a 2\%-5\% reduction of $\mathrm{InsP}_{3}$ and even under stimulation these levels do not show any increase [135]. In normal conditions no obvious phenotypic alterations were detected, while, as expected, Ins $\mathrm{P}_{3}$-mediated responses, such as gravitropism, were delayed in the InsP 5Ptase overexpressing transgenic plants. Surprisingly, human InsP 5Ptase plants were more drought tolerant [132], an unexpected finding based on the classical $\mathrm{Ins}_{3}$ signaling paradigm that predicts decreased levels of $\mathrm{Ins}_{3}$ and calcium would decrease stomatal closure and therefore drought tolerance. This finding might explain the contrasting response to ABA during seed germination observed in common bean and Arabidopsis lpa mutants (see above).

As already mentioned, elevated $\mathrm{InsP}_{3}$ has been shown to correlate with downstream responses to ABA and sugars [107,108]. A plant inositol polyphosphate 5-phosphatase (5Ptase13; At1g05630) has been shown to be involved in linking myo-inositol signaling to sugar sensing and stress response [136]. The 5Ptase13 protein contains a WD40 repeat region that specifically interacts with a Sucrose non fermenting-1-1Related Kinase (SnRK1.1), which functions as a sensor of energy and stress in plants [137]. When sugars are in limited supply, 5Ptase13 interacts with SnRK1.1 and prevents its proteosomal degradation, resulting in transcriptional induction of genes involved in low nutrients/stress response [110,115]. Several other developmental/signaling defects, altering blue light response, gravitropism, and vesicular trafficking for PIN mediated auxin transport have been reported in 5Ptase13 mutants, indicating that hydrolysis of $\operatorname{Ins}(1,4,5) \mathrm{P}_{3}$ or $\operatorname{PtdIns}(4,5) \mathrm{P}_{2}$ are critical for plant development and signaling [138,139].

Inositol polyphosphate kinase (IPK2) is a key component for Ins $\mathrm{P}_{3}$ turnover, as it phosphorylates $\operatorname{Ins}(1,4,5) \mathrm{P}_{3}$ successively at the 6- and 3-positions to generate $\operatorname{Ins}(1,4,5,6) \mathrm{P}_{4}$ and $\operatorname{Ins}(1,3,4,5,6) \mathrm{P}_{5}$, respectively, and IPK2 has very important regulatory roles, indicated by subcellular localization in both the nucleus and cytoplasm (discussed below). Downregulation of AtIPK2 $\alpha$ through antisense 
inhibition has been shown to result in enhanced root growth and pollen germination [56]. Since application of $\mathrm{InsP}_{3}$ can enhance root growth, most likely AtIPK2 $\alpha$ silencing may cause the accumulation of $\mathrm{InsP}_{3}$ in addition to the expected depletion of $\mathrm{InsP}_{4}$ and $\mathrm{InsP}_{5}$.

\subsection{Vesicle Trafficking and Polar Auxin Transport}

A number of lpa mutants displays severe defects in embryo and/or plant development, and this often occurs when MIPS genes are mutated or their expression is greatly altered $[44,45,88]$ (Table S1). In developing seeds MIPS genes are highly expressed, suggesting an important role of myo-inositol in seed/embryo development. Using double and triple mips mutants of Arabidopsis, which display phenotypes resembling those of auxin mutants, it has been shown that MIPS-mediated de novo synthesis of myo-inositol is essential for maintaining the normal function of endomembrane trafficking and for maintaining endomembrane structure. This is critical for correct auxin transport and thus for correct auxin localization during embryo pattern formation [44]. PtdIns contributes $21 \%$ of the phospholipids in nonphotosynthetic plant membranes, and the various phosphorylated forms of PtdIns have critical roles in cytoskeletal rearrangements, membrane trafficking, and organelle labeling. Indeed, the finding that Arabidopsis mips1/mips3 double mutants can be rescued by over-expressing the phosphatidyl synthase 2 gene (AtPIS2), controlling the entry point for PtdIns synthesis, supports the hypothesis that PtdIns and phosphatidylinositides are essential for endomembrane structure and trafficking [44]. Another study showed that the atmips1 mutant has reduced levels of PtdIns and altered trafficking of the auxin efflux carrier PIN2 [98,106], suggesting that lower PtdIns content negatively impacts on vesicular trafficking of PIN2. Interestingly, the atmips1 phenotype was evident only if plants were grown under high light intensity conditions (higher than $160 \mu \mathrm{mol} \mathrm{m} \mathrm{m}^{-2} \cdot \mathrm{s}^{-1}$ ) [44]. Although currently not intensely studied, it is likely that not only PIN proteins but also many other membrane proteins will depend on PtdIns to reach their membrane destinations. This may indicate other obvious and broad ramifications of inositol metabolisms in plant function [100]. The critical role of myo-inositol as precursor of PtdIns species is also confirmed by the finding that $\mathrm{InsP}_{3}$ is linked to $\mathrm{Ca}^{2+}$ signaling and control of directional auxin transport mediated by polar PIN auxin transporters [140]. During a screen for suppressors of PIN1 overexpression, Zhang et al., isolated an Arabidopsis mutant (supo1) affected in an inositol phosphate 1-phosphatase known as SAL1/FRY1 [114]. The mutant had increased $\mathrm{InsP}_{3}$ and cytosolic $\mathrm{Ca}^{2+}$ levels and was able to restore a wild type phenotype in 35S::PIN1 seedlings. PIN overexpressing plants have short roots, agravitropic root growth, and elevated auxin in root tips, presumably caused by the ectopic presence of basally localized PIN1 in the epidermal cells.

Involvement of InsP metabolism in auxin mediated processes is also provided by the finding that plants over-expressing the AtIPK2 $\beta$ gene show an attenuation of the inhibition of IAA induced primary root elongation. This indicates that AtIPK2 $\beta$ can negatively regulate auxin signaling [57]. At least in part, this regulation is transcriptional, since AtIPK2 $\beta$ over-expressing plants repress the expression of CYP83B1 (involved in auxin biosynthesis), MAX4 and SPS (required for auxin-mediated bud inhibition and outgrowth), and stimulate PIN4 expression [57]. 


\subsection{Biotic and Abiotic Stress Response}

Limiting PtdIns synthesis and/or InsP 6 content may also impact plant defense response. The Arabidopsis atmips1 mutant showed enhanced resistance to pathogens and spontaneous cell death, thus implying that MIPS is a repressor of programmed cell death (PCD) [97]. In this mutant decreased contents of myo-inositol, ascorbic acid and PtdIns correlated with elevated ceramide levels, sphingolipid precursors associated to cell death. The hypothesis is that spontaneous cell death is the result of altered oxidative stress sensitivity, induced by changes in myo-inositol, galactinol, and ascorbic acid, along with elevated ceramides and hydroxyceramides that result from decreased PtdIns availability for sphingolipid production [111]. Myo-inositol metabolism and defense response are also linked to carbohydrate metabolism, as a mutation in the hexokinase 1 (HXK1) enzyme has been shown to suppress mips1 light-dependent PCD, indicating an epistatic relationship between mips1 and hxk1 mutants [141].

Like other enzymes of the InsP 6 biosynthetic pathway (see below), MIPS has a double cellular localization: cytosolic and nuclear. Interestingly, in a recent work in Arabidopsis, it has been demonstrated that MIPS1 protein binds directly to its own promoter to stimulate transcription by locally inhibiting the activation of ARABIDOPSIS TRITHORAX-RELATED 5 and 6 (ATXR5 and 6)-dependent heterochromatin marks generated by a transposable element [123]. Upon activation of pathogen response, elicited by bacterial flagellin (flg22) treatment, the inhibitory action of MIPS1 on ATXR5/6 is alleviated and expression of MIPS1 decreases. This dual function of MIPS1 may ensure MIPS1 gene expression under normal growth conditions, and its down-regulation during pathogen attack to induce PCD [123]. It would be very interesting to verify if such regulatory mechanism is specific to Arabidopsis or is present in other plants.

Impaired resistance to wounding and herbivory has also been reported in transgenic plants in which inositol polyphosphates are globally reduced through expressing a human type I InsP 5-Ptase. In this case, plants treated with flg22 show impaired $\mathrm{Ca}^{2+}$ elevation, accompanied by a decrease in the expression of several defense related genes, suggesting that the inability to propagate an $\mathrm{InsP}_{3}$ signal is the primary basis for the altered defense response observed [142]. Other evidence for the involvement of InsPs in wound signaling comes from work on atipk1-1 mutants, which exhibit a pathogen hypersensitive phenotype and increased defense capability via jasmonate receptor COI1-mediated processes, including wound-induced gene expression, defense against caterpillars or root growth inhibition by jasmonate $[48,143]$.

Perturbations of the $\mathrm{InsP}_{6}$ pathway have been reported to alter plant response to environmental stimuli. For instance, heterologous expression of AtIPK2 $\beta$ in tobacco leads to improved tolerance to diverse abiotic stresses (osmotic, drought, freezing temperature, oxidative stress) [58]. Similar results have been obtained by over-expressing the IbMIPS1 gene in sweet potato (Ipomoea batatas L. Lam.). Transgenic plants showed significantly enhanced salt and drought tolerance, and stem nematode resistance. Following exposure to salt and nematode stresses, transcriptome analysis revealed up-regulation of MIPS and IMP genes, together with genes for phosphatidylinositol and ABA signaling pathways, stress responses and ROS-scavenging [144]. 


\subsection{Nuclear Functions and Regulation of Phosphorus Homeostasis}

A central issue in InsP metabolism is the cellular localization of InsP pools. Dual localization, cytosolic and nuclear, of inositol phosphates and of their biosynthetic enzymes is well documented in yeast [145] and has been demonstrated in plants for many enzymes of the $\mathrm{InsP}_{6}$ pathway, including a number of phosphatidylinositol kinases, AtMIPS1, AtIPK2 $\alpha$, AtIPK2 $\beta$, AtIPK1 and AtITPK1 $[56,64,98,122,123,146]$.

In yeast, the transcriptional activation of $\mathrm{PHO}$ genes in response to $\mathrm{P}_{\mathrm{i}}$ deficiency is coordinated with regulated chromatin remodeling [145]. Furthermore, a number of InsPs species have been shown to participate to transcriptional gene regulation via chromatin remodeling and histone modification [147]. For example, proper expression of INO1, coding inositol 1-phosphate synthase, involves integration of INO80 and SNF, and ISW2, which act as positive or negative regulators of transcription, respectively. $\mathrm{InsP}_{4}$ and $\mathrm{InsP}_{5}$ have also been shown to stimulate nucleosome mobilization by the SWI/SNF complex. On the contrary, InsP6 inhibits nucleosome mobilization by NURF, ISW2 and INO80 complexes [148]. The yeast IPK2 and its products, $\mathrm{Ins}_{4}$ and $\mathrm{InsP}_{5}$, are involved in transcriptional regulation in response to environmental and nutritional stresses. IPK2 has been shown to be allelic to Arg82/ArgRIII, a component of the ArgR-Mcm 1 transcriptional complex that regulates gene expression for arginine metabolism [149]. IPK2 is also required for the induction of some phosphate responsive genes (PSR), like $\mathrm{PHO5}$, by modulating the chromatin remodeling complexes SWI/SNF and INO80, under normal $\mathrm{P}_{\mathrm{i}}$ supply [150]. Xia and coworkers [146] demonstrated that Arabidopsis AtIPK2 $\beta$ is able to complement a yeast Arg82/ArgRIII mutant lacking a functional ArgR-Mcm1 transcription complex. However, no data are available to support a similar role for AtIPK2 $\beta$ in PSR gene induction, as was shown in yeast.

Plant $\mathrm{P}_{\mathrm{i}}$ homeostasis is a highly regulated process, and involves the perception of $\mathrm{P}_{\mathrm{i}}$ present in the environment, followed by acquisition, remobilization and recycling of $\mathrm{P}_{\mathrm{i}}$ [151]. The Arabidopsis mutant atipk1-1 exhibits an 83\% reduction in seed $\mathrm{InsP}_{6}$, along with an increase in $\mathrm{InsP}_{4}$ and $\mathrm{InsP}_{5}$ in seed and vegetative tissues. Furthermore, atipk1-1 plants show longer root hairs and aberrant phosphate sensing. The plants behave as if they were in a phosphorous-limiting environment, indicating a role of IPK1 in the regulation of $\mathrm{P}_{\mathrm{i}}$ acquisition machinery [55].

In a recent work, transcriptional analysis of roots of atipk1-1 mutants showed perturbations of a subset of $\mathrm{P}_{i}$ starvation responsive genes, together with increased expression of genes involved in $\mathrm{P}_{\mathrm{i}}$ uptake, allocation and remobilization [122]. The authors observed that the transcriptional activation correlate with reduction of the chromatin association of histone variant H2A.Z. In yeast the $\mathrm{P}_{\mathrm{i}}$ responsive genes $\mathrm{PHO} 5$ and $\mathrm{PHO} 84$ require $\mathrm{InsP}_{4}$ and $\mathrm{InsP}_{5}$ for proper remodeling of chromatin structure [150], thus it might be speculated that in plants, specific InsPs species serve as signals and regulate the eviction of H2A.Z from PSR genes.

Perturbation of $\mathrm{P}_{\mathrm{i}}$ and sulfate $\left(\mathrm{SO}_{4}\right)$ homeostasis and signaling have been observed in lpa plants obtained by over-expressing a bacterial phytase in Arabidopsis [152]. These plants (PHY-US417) showed up to $50 \%$ and $45 \%$ increases in shoot $\mathrm{P}_{\mathrm{i}}$ and $\mathrm{SO}_{4}$ concentrations, respectively, and improved plant growth with enhanced root growth capacity in $\mathrm{P}_{\mathrm{i}}$ deficiency. These findings were supported by expression analysis of a subset of genes coding for $\mathrm{P}_{\mathrm{i}}$ transporters (PHT1,1, PHT1,4, PHO1 and $\mathrm{PHO1}, \mathrm{H1}$ ) and $\mathrm{SO}_{4}(\mathrm{SULTR} 1,2)$, the expression of which was upregulated in both overexpressing 
PHY-US417 and atipk1-1 plants. Interestingly, overexpressing PHY-US417 transgenic plants and the atipk1-1 also showed a stronger remobilization of iron during germination.

One of the key points for proper gene expression is the regulation of nuclear export of mRNA, a process that requires the directional translocation of mRNA-ribonucleoprotein particles (mRNPs) through nuclear pore complexes (NPCs). In eukaryotes, Gle1 is a component of the NPC. In yeast, Gle1 and its cofactor InsP 6 activate the DEAD-box ATPase, Dbp5, to allow mRNA export at the NPC. Gle1 is also found in the cytosol, where it plays a role in translation initiation and termination in Dbp5-independent and -dependent manners, respectively [145]. In a very recent work, Lee et al. [124] showed that plant Gle1, in conjunction with InsP $_{6}$, functions as an activator of the ATPase/RNA helicase LOS4 (low expression of osmotically responsive genes 4, homolog of yeast Dbp5), which is involved in mRNA export in plants, supporting the Gle1-Ins $\mathrm{P}_{6}$-Dbp5 paradigm proposed in yeast. Interestingly, an ipk1 mutant has been shown to be defective in nuclear mRNA export, however, the ectopic expression of Gle1 variants with enhanced $\mathrm{InsP}_{6}$ sensitivity was able to rescue the mRNA export defect of the ipk1 mutant. Moreover, a significant improvement of vegetative growth, seed yield, and seed performance of the mutant was observed, suggesting that Gle1 is an important factor responsible for mediating $\mathrm{Ins}_{6}$ functions in plant growth and reproduction [124].

\subsection{Hormonal Signaling}

In recent years, it was discovered that two important phytohormone receptors, TIR1 and COI1, required for auxin and jasmonic acid (JA) signaling, respectively, contain InsPs as structural cofactors, thus widening the regulatory roles involving the InsP6 pathway [126,153]. TIR1 is part of the ubiquitin E3 ligase complex $\mathrm{SCF}^{\mathrm{TIR} 1}$. Upon auxin binding, it recruits specific transcriptional repressors (the Aux/IAA repressors) for ubiquitination by the SCF complex. This marking process leads to the degradation of the repressors by the proteasome, alleviating repression and leading to expression of specific auxin responsive genes [154]. The determination of the crystal structure of TIR1 revealed the presence of an InsP6 molecule bound in close proximity to the auxin binding pocket [126]. In a similar way, COI1 is the F-box component of a SCF ubiquitin E3 ligase complex that recruits Jasmonate ZIM-domain (JAZ) transcriptional repressors upon binding to the bioactive JA-isoleucin conjugate (JA-Ile). This triggers JAZ polyubiquitination and subsequent proteasomal degradation, and results in de-repression of MYC2 dependent transcription of jasmonate repsponsive genes [154]. Analysis of the crystal structure of the JA receptor revealed a binding pocket comprised of COI1, bound to JAZ, and containing an $\mathrm{Ins}_{5}$ molecule as a structural cofactor [154]. Arabidopsis ipk1 mutants, that have elevated levels of InsP $\mathrm{P}_{5}$ and display enhanced wound-induction of various defense genes, were found to be more sensitive towards exogenous methyl-JA, and exhibited increased defensive capacity against caterpillar herbivory [143], supporting the importance of $\mathrm{InsP}_{5}$ contribution to COI1 function. However, very recently, a link between $\mathrm{InsP}_{8}$ and jasmonate-dependent defense has been discovered. The authors do not rule out that other inositol polyphosphates, other than $\mathrm{InsP}_{8}$, may influence assembly of the jasmonate receptor complex [127], but insect larvae feeding on Arabidopsis vih2 mutant plants (unable to synthesize InsP 8 , Figure 1) showed a significant weight increase compared with larvae feeding on control plants, indicating that VIH2 plays a role in activating defenses that interfere with insect herbivore development. Furthermore, molecular data indicate that vih2 plants are defective in jasmonate perception. 


\section{Conclusions}

This object of this review is to integrate current knowledge about different aspects of phytic acid pathway and lpa mutants with the most recent literature concerning the regulatory roles of the multiple components of the pathway in cell signaling and plant processes. In the last decade, the range of important crop plants with lpa mutants has expanded rapidly. Known lpa mutants have seed phytic acid reductions ranging from $10 \%$ to $90 \%$, and in many cases their improved value in animal and human nutrition has been demonstrated. However, good agronomic performance and yield stability are still challenging for Ipa mutants in many crops. In no case were these mutants due to a spontaneous mutation, underlying the important role of $\mathrm{InsP}_{6}$ pathway for the plant. The increasing number of plant processes in which phytic acid and its metabolism have been shown to play a key role clearly indicates that we need to increase our knowledge of the role of InsPs and phytic acid in the integration and functioning of metabolic and hormonal signaling pathways and in response to biotic and abiotic stresses. This knowledge will be fundamental to understand how far we may go to obtain stable and productive lpa mutants in different crops and how to drive their genetic improvement.

\section{Supplementary Materials}

Supplementary materials can be accessed at: http://www.mdpi.com/2223-7747/4/4/728/s1.

\section{Acknowledgments}

This work was partially supported by Programme FILAGRO "Strategie innovative e sostenibili per la filiera agroalimentare", as part of the activities defined within the Accordo Quadro Consiglio Nazionale delle Ricerche and Regione Lombardia, and by CERES - "NewPearl" project, jointly funded by Fondazione Cariplo and Agropolis Fondation.

\section{Conflicts of Interest}

The authors declare no conflict of interest.

\section{Abbreviations}

Ins, myo-inositol; InsPs, inositol phosphates; InsP6, myo-inositol-1,2,3,4,5,6-hexakisphosphate; MIPS, myo-inositol-3-phosphate synthase; IMP, myo-inositol-phosphate monophosphatase; MIK, myo-inositol kinase; IPK1, inositol polyphosphate 2-kinase; ITPK, the inositol 1,3,4-trisphosphate 5-/6kinase; IPK2, inositol 1,4,5-tris-phosphate kinase.

\section{References}

1. Shears, S. Assessing the omnipotence of inositol hexakisphosphate. Cell. Signal. 2001, 13, 151-158.

2. Coelho, C.; Tsai, S.; Vitorello, V. Dynamics of inositol phosphate pools (tris-, tetrakis- and pentakisphosphate) in relation to the rate of phytate synthesis during seed development in common bean (Phaseolus vulgaris). J. Plant Physiol. 2005, 162, 1-9. 
3. Hatzack, F.; Johansen, K.; Rasmussen, S. Nutritionally relevant parameters in low-phytate barley (Hordeum vulgare L.) grain mutants. J. Agric. Food Chem. 2000, 48, 6074-6080.

4. Ogawa, M.; Tanaka, K.; Kasai, Z. Phytic acid formation in dissected ripening rice grains. Agric. Biol. Chem. 1979, 43, 2211-2213.

5. Otegui, M.; Capp, R.; Staehelin, L. Developing seeds of Arabidopsis store different minerals in two types of vacuoles and in the endoplasmic reticulum. Plant Cell 2002, 14, 1311-1327.

6. Greenwood, J.; Gifford, D.; Bewley, J. Seed development in Ricinus-communis cv Hale (astor bean) 2. Accumulation of phytic acid in the developing endosperm and embryo in relation to the deposition of lipid, protein, and phosphorus. Can. J. Bot. 1984, 62, 255-261.

7. Greenwood, J.; Bewley, J.D. Seed development in Ricinus-communis cv Hale (astor bean). 3. Pattern of storage protein and phytin accumulation in the endosperm. Can. J. Bot. 1985, 63, 2121-2128.

8. O’Dell, B.L.; de Boland, A.R.; Koirtyohann, S.T. Distribution of phytate and nutritionally important elements among the morphological components of cereal grains. J. Agric. Food Chem. 1972, 20, $718-721$.

9. Ariza-Nieto, M.; Blair, M.; Welch, R.; Glahn, R. Screening of iron bloavallability patterns in eight bean (Phaseolus vulgaris L.) genotypes using the Caco-2 cell in vitro model. J. Agric. Food Chem. 2007, 55, 7950-7956.

10. Raboy, V. Myo-inositol-1,2,3,4,5,6-hexakisphosphate. Phytochemistry 2003, 64, 1033-1043.

11. Raboy, V. Seeds for a better future: "Low phytate", grains help to overcome malnutrition and reduce pollution. Trends Plant Sci. 2001, 6, 458-462.

12. Schlemmer, U.; Frølich, W.; Prieto, R.M.; Grases, F. Phytate in foods and significance for humans: Food sources, intake, processing, bioavailability, protective role and analysis. Mol. Nutr. Food Res. 2009, 53, S330-S375.

13. Leytem, A.B.; Maguire, R.O. Environmental implications of inositol phosphates in animal manures. In Inositol Phosphates: Linking Agriculture and the Environment; Turner, B.L., Richardson, A.E., Mullaney, E.J., Eds.; CAB International: Wallingford, UK, 2007; pp. 150-168.

14. Raboy, V. Approaches and challenges to engineering seed phytate and total phosphorus. Plant Sci. 2009, 177, 281-296.

15. Gerke, J. Phytate (inositol hexakisphosphate) in soil and phosphate acquisition from inositol phosphates by higher plants. A review. Plants 2015, 4, 253-266.

16. Lott, J.; Ockenden, I.; Raboy, V.; Batten, G. Phytic acid and phosphorus in crop seeds and fruits: A global estimate. Seed Sci. Res. 2000, 10, 11-33.

17. Rose, T.; Liu, L.; Wissuwa, M. Improving phosphorus efficiency in cereal crops: Is breeding for reduced grain phosphorus concentration part of the solution? Front. Plant Sci. 2013, 4, doi:10.3389/fpls.2013.00444.

18. Raboy, V.; Cichy, K.; Peterson, K.; Reichman, S.; Sompong, U.; Srinives, P.; Saneoka, H. Barley (Hordeum vulgare L.) low phytic acid 1-1: An endosperm-specific, filial determinant of seed total phosphorus. J. Hered. 2014, 105, 656-665.

19. Torabinejad, J.; Donahue, J.; Gunesekera, B.; Allen-Daniels, M.; Gillaspy, G. VTC4 is a bifunctional enzyme that affects myoinositol and ascorbate biosynthesis in plants. Plant Physiol. 2009, 150, 951-961. 
20. Laing, W.; Bulley, S.; Wright, M.; Cooney, J.; Jensen, D.; Barraclough, D.; MacRae, E. A highly specific L-galactose-1-phosphate phosphatase on the path to ascorbate biosynthesis. Proc. Natl. Acad. Sci. USA 2004, 101, 16976-16981.

21. Shi, J.; Wang, H.; Hazebroek, J.; Ertl, D.; Harp, T. The maize low-phytic acid 3 encodes a myo-inositol kinase that plays a role in phytic acid biosynthesis in developing seeds. Plant $J$. 2005, 42, 708-719.

22. Kim, S.; Tai, T. Genetic analysis of two OsLpa1-like genes in Arabidopsis reveals that only one is required for wild-type seed phytic acid levels. Planta 2010, 232, 1241-1250.

23. Kim, S.; Andaya, C.; Newman, J.; Goyal, S.; Tai, T. Isolation and characterization of a low phytic acid rice mutant reveals a mutation in the rice orthologue of maize MIK. Theor. Appl. Genet. 2008, 117, 1291-1301.

24. Odom, A.; Stahlberg, A.; Wente, S.; York, J. A role for nuclear inositol 1,4,5-trisphosphate kinase in transcriptional control. Science 2000, 287, 2026-2029.

25. Kim, S.; Andaya, C.; Goyal, S.; Tai, T. The rice OsLpa1 gene encodes a novel protein involved in phytic acid metabolism. Theor. Appl. Genet. 2008, 117, 769-779.

26. Tagashira, Y.; Shimizu, T.; Miyamoto, M.; Nishida, S.; Yoshida, K. Overexpression of a gene involved in phytic acid biosynthesis substantially increases phytic acid and total phosphorus in rice seeds. Plants 2015, 4, 196-208.

27. Sparvoli, F.; Cominelli, E. Phytate transport by MRPs. In Plant ABC Transporters; Gesler, M., Ed.; Springer: Berlin, Germany, 2014; Volume 22, pp. 19-38.

28. Phillippy, B.; Ullah, A.; Ehrlich, K. Purification and some properties of inositol 1,3,4,5,6-pentakisphosphate 2-kinase from immature soybean seeds. J. Biol. Chem. 1994, 269, 28393-28399.

29. Phillippy, B. Identification of inositol 1,3,4-trisphosphate 5-kinase and inositol 1,3,4,5-tetrakisphosphate 6-kinase in immature soybean seeds. Plant Physiol. 1998, 116, 291-297.

30. Stevenson-Paulik, J.; Odom, A.; York, J. Molecular and biochemical characterization of two plant inositol polyphosphate 6-/3-/5-kinases. J. Biol. Chem. 2002, 277, 42711-42718.

31. Sweetman, D.; Johnson, S.; Caddick, S.; Hanke, D.; Brearley, C. Characterization of an Arabidopsis inositol 1,3,4,5,6-pentakisphosphate 2-kinase (AtIPK1). Biochem. J. 2006, 394, 95-103.

32. Sweetman, D.; Stavridou, I.; Johnson, S.; Green, P.; Caddick, S.; Brearley, C. Arabidopsis thaliana inositol 1,3,4-trisphosphate 5/6-kinase 4 (AtITPK4) is an outlier to a family of ATP-grasp fold proteins from Arabidopsis. FEBS Lett. 2007, 581, 4165-4171.

33. Sun, Y.; Thompson, M.; Lin, G.; Butler, H.; Gao, Z.; Thornburgh, S.; Yau, K.; Smith, D.; Shukla, V. Inositol 1,3,4,5,6-pentakisphosphate 2-kinase from maize: Molecular and biochemical characterization. Plant Physiol. 2007, 144, 1278-1291.

34. Josefsen, L.; Bohn, L.; Sorensen, M.; Rasmussen, S. Characterization of a multifunctional inositol phosphate kinase from rice and barley belonging to the ATP-grasp superfamily. Gene 2007, 397, 114-125.

35. Kim, S.; Tai, T. Identification of genes necessary for wild-type levels of seed phytic acid in Arabidopsis thaliana using a reverse genetics approach. Mol. Genet. Genom. 2011, 286, 119-133. 
36. Suzuki, M.; Tanaka, K.; Kuwano, M.; Yoshida, K. Expression pattern of inositol phosphate-related enzymes in rice (Oryza sartiva L.): Implications for the phytic acid biosynthetic pathway. Gene 2007, 405, 55-64.

37. Fileppi, M.; Galasso, I.; Tagliabue, G.; Daminati, M.; Campion, B.; Doria, E.; Sparvoli, F. Characterisation of structural genes involved in phytic acid biosynthesis in common bean (Phaseolus vulgaris L.). Mol. Breed. 2010, 25, 453-470.

38. Bhati, K.; Aggarwal, S.; Sharma, S.; Mantri, S.; Singh, S.; Bhalla, S.; Kaur, J.; Tiwari, S.; Roy, J.; Tuli, R.; et al. Differential expression of structural genes for the late phase of phytic acid biosynthesis in developing seeds of wheat (Triticum aestivum L.). Plant Sci. 2014, 224, 74-85.

39. Stiles, A.; Qian, X.; Shears, S.; Grabau, E. Metabolic and signaling properties of an ITPK gene family in glycine max. FEBS Lett. 2008, 582, 1853-1858.

40. Chappell, A.; Scaboo, A.; Wu, X.; Nguyen, H.; Pantalone, V.; Bilyeu, K. Characterization of the MIPS gene family in Glycine max. Plant Breed. 2006, 125, 493-500.

41. Larson, S.; Raboy, V. Linkage mapping of maize and barley myo-inositol 1-phosphate synthase dna sequences: Correspondence with a low phytic acid mutation. Theor. Appl. Genet. 1999, 99, 27-36.

42. Yoshida, K.; Wada, T.; Koyama, H.; Mizobuchi-Fukuoka, R.; Naito, S. Temporal and spatial patterns of accumulation of the transcript of myo-inositol-1-phosphate synthase and phytin-containing particles during seed development in rice. Plant Physiol. 1999, 119, 65-72.

43. Hitz, W.; Carlson, T.; Kerr, P.; Sebastian, S. Biochemical and molecular characterization of a mutation that confers a decreased raffinosaccharide and phytic acid phenotype on soybean seeds. Plant Physiol. 2002, 128, 650-660.

44. Luo, Y.; Qin, G.; Zhang, J.; Liang, Y.; Song, Y.; Zhao, M.; Tsuge, T.; Aoyama, T.; Liu, J.; $\mathrm{Gu}, \mathrm{H}$; et al. D-myo-inositol-3-phosphate affects phosphatidylinositol-mediated endomembrane function in Arabidopsis and is essential for auxin-regulated embryogenesis. Plant Cell 2011, 23, 1352-1372.

45. Nunes, A.; Vianna, G.; Cuneo, F.; Amaya-Farfan, J.; de Capdeville, G.; Rech, E.; Aragao, F. Rnai-mediated silencing of the myo-inositol-1-phosphate synthase gene (GmMIPS1) in transgenic soybean inhibited seed development and reduced phytate content. Planta 2006, 224, 125-132.

46. Kuwano, M.; Mimura, T.; Takaiwa, F.; Yoshida, K. Generation of stable "low phytic acid" transgenic rice through antisense repression of the 1D-myo-inositol 3-phosphate synthase gene (RINO1) using the 18-kda oleosin promoter. Plant Biotechnol. J. 2009, 7, 96-105.

47. Yuan, F.; Zhao, H.; Ren, X.; Zhu, S.; Fu, X.; Shu, Q. Generation and characterization of two novel low phytate mutations in soybean (Glycine max L. Merr.). Theor. Appl. Genet. 2007, 115, 945-957.

48. Murphy, A.; Otto, B.; Brearley, C.; Carr, J.; Hanke, D. A role for inositol hexakisphosphate in the maintenance of basal resistance to plant pathogens. Plant J. 2008, 56, 638-652.

49. Mitsuhashi, N.; Kondo, M.; Nakaune, S.; Ohnishi, M.; Hayashi, M.; Hara-Nishimura, I.; Richardson, A.; Fukaki, H.; Nishimura, M.; Mimura, T. Localization of myo-inositol-1-phosphate synthase to the endosperm in developing seeds of Arabidopsis. J. Exp. Bot. 2008, 59, 3069-3076.

50. Chiera, J.; Grabau, E. Localization of myo-inositol phosphate synthase (GmMIPS-1) during the early stages of soybean seed development. J. Exp. Bot. 2007, 58, 2261-2268. 
51. Fu, J.; Peterson, K.; Guttieri, M.; Souza, E.; Raboy, V. Barley (Hordeum vulgare L.) inositol monophosphatase: Gene structure and enzyme characteristics. Plant Mol. Biol. 2008, 67, 629-642.

52. Gillaspy, G.E.; Keddie, J.S.; Oda, K.; Gruissem, W. Plant inositol monophosphatase is a lithium-sensitive enzyme encoded by a multigene family. Plant Cell 1995, 7, 2175-2185.

53. Nourbakhsh, A.; Collakova, E.; Gillaspy, G.E. Characterization of the inositol monophosphatase gene family in Arabidopsis. Front. Plant Sci. 2014, 5, 725, doi:10.3389/fpls.2014.00725.

54. Sato, Y.; Yazawa, K.; Yoshida, S.; Tamaoki, M.; Nakajima, N.; Iwai, H.; Ishii, T.; Satoh, S. Expression and functions of myo-inositol monophosphatase family genes in seed development of Arabidopsis. J. Plant Res. 2011, 124, 385-394.

55. Stevenson-Paulik, J.; Bastidas, R.; Chiou, S.; Frye, R.; York, J. Generation of phytate-free seeds in Arabidopsis through disruption of inositol polyphosphate kinases. Proc. Natl. Acad. Sci. USA 2005, 102, 12612-12617.

56. Xu, J.; Brearley, C.A.; Lin, W.H.; Wang, Y.; Ye, R.; Mueller-Roeber, B.; Xu, Z.H.; Xue, H.W. A role of Arabidopsis inositol polyphosphate kinase, AtIPK2 $\alpha$, in pollen germination and root growth. Plant Physiol. 2005, 137, 94-103.

57. Zhang, Z.B.; Yang, G.; Arana, F.; Chen, Z.; Li, Y.; Xia, H.J. Arabidopsis inositol polyphosphate 6-/3-kinase (AtIPK2 $\beta$ ) is involved in axillary shoot branching via auxin signaling. Plant Physiol. 2007, 144, 942-951.

58. Yang, L.; Tang, R.; Zhu, J.; Liu, H.; Mueller-Roeber, B.; Xia, H.; Zhang, H. Enhancement of stress tolerance in transgenic tobacco plants constitutively expressing AtIPK2 $\beta$, an inositol polyphosphate 6-/3-kinase from Arabidopsis thaliana. Plant Mol. Biol. 2008, 66, 329-343.

59. Wilson, M.; Majerus, P. Characterization of a cDNA encoding Arabidopsis thaliana inositol 1,3,4-trisphosphate 5/6-kinase. Biochem. Biophys. Res. Commun. 1997, 232, 678-681.

60. Chen, Q.; Niu, X.; Chai, M.; Chen, J.; Liu, Q.; Wang, X. Isolation of an Arabidopsis gene encoding Ins $(1,3,4)$ p-3 5/6-kinase-like protein and involved in plant response to abiotic stresses. Acta Bot. Sin. 2003, 45, 211-218.

61. Raboy, V.; Gerbasi, P.; Young, K.; Stoneberg, S.; Pickett, S.; Bauman, A.; Murthy, P.; Sheridan, W.; Ertl, D. Origin and seed phenotype of maize low phytic acid 1-1 and low phytic acid 2-1. Plant Physiol. 2000, 124, 355-368.

62. Shi, J.; Wang, H.; Wu, Y.; Hazebroek, J.; Meeley, R.; Ertl, D. The maize low-phytic acid mutant $1 p a 2$ is caused by mutation in an inositol phosphate kinase gene. Plant Physiol. 2003, 131, 507-515.

63. Kim, S.; Tai, T. Identification of novel rice low phytic acid mutations via TILLING by sequencing. Mol. Breed. 2014, 34, 1717-1729.

64. Qin, Z.X.; Chen, Q.J.; Tong, Z.; Wang, X.C. The Arabidopsis inositol 1,3,4-trisphosphate 5/6 kinase, AtITPK-1, is involved in plant photomorphogenesis under red light conditions, possibly via interaction with COP9 signalosome. Plant Physiol. Biochem. 2005, 43, 947-954.

65. Yuan, F.; Zhu, D.; Tan, Y.; Dong, D.; Fu, X.; Zhu, S.; Li, B.; Shu, Q. Identification and characterization of the soybean IPK1 ortholog of a low phytic acid mutant reveals an exon-excluding splice-site mutation. Theor. Appl. Genet. 2012, 125, 1413-1423.

66. Shi, J.; Wang, H.; Schellin, K.; Li, B.; Faller, M.; Stoop, J.; Meeley, R.; Ertl, D.; Ranch, J.; Glassman, K. Embryo-specific silencing of a transporter reduces phytic acid content of maize and soybean seeds. Nat. Biotech. 2007, 25, 930-937. 
67. Nagy, R.; Grob, H.; Weder, B.; Green, P.; Klein, M.; Frelet-Barrand, A.; Schjoerring, J.; Brearley, C.; Martinoia, E. The Arabidopsis ATP-binding cassette protein AtMRP5/AtABCC5 is a high affinity inositol hexakisphosphate transporter involved in guard cell signaling and phytate storage. J. Biol. Chem. 2009, 284, 33614-33622.

68. Klein, M.; Perfus-Barbeoch, L.; Frelet, A.; Gaedeke, N.; Reinhardt, D.; Mueller-Roeber, B.; Martinoia, E.; Forestier, C. The plant multidrug resistance ABC transporter AtMRP5 is involved in guard cell hormonal signalling and water use. Plant J. 2003, 33, 119-129.

69. Suh, S.J.; Wang, Y.F.; Frelet, A.; Leonhardt, N.; Klein, M.; Forestier, C.; Mueller-Roeber, B.; Cho, M.H.; Martinoia, E.; Schroeder, J.I. The ATP binding cassette transporter AtMRP5 modulates anion and calcium channel activities in Arabidopsis guard cells. J. Biol. Chem. 2007, 282, 1916-1924.

70. Klein, M.; Burla, B.; Martinoia, E. The multidrug resistance-associated protein (MRP/ABCC) subfamily of ATP-binding cassette transporters in plants. FEBS Lett. 2006, 580, 1112-1122.

71. Wanke, D.; Kolukisaoglu, H. An update on the ABCC transporter family in plants: Many genes, many proteins, but how many functions? Plant Biol. 2010, 12, 15-25.

72. Kang, J.; Park, J.; Choi, H.; Burla, B.; Kretzschmar, T.; Lee, Y.; Martinoia, E. Plant ABC transporters. Arab. Book 2011, 9, e0153.

73. Xu, X.; Zhao, H.; Liu, Q.; Frank, T.; Engel, K.; An, G.; Shu, Q. Mutations of the multi-drug resistance-associated protein $\mathrm{ABC}$ transporter gene 5 result in reduction of phytic acid in rice seeds. Theor. Appl. Genet.2009, 119, 75-83.

74. Gaedeke, N.; Klein, M.; Kolukisaoglu, U.; Forestier, C.; Muller, A.; Ansorge, M.; Becker, D.; Mamnun, Y.; Kuchler, K.; Schulz, B.; et al. The Arabidopsis thaliana ABC transporter AtMRP5 controls root development and stomata movement. EMBO J. 2001, 20, 1875-1887.

75. Winter, D.; Vinegar, B.; Nahal, H.; Ammar, R.; Wilson, G.; Provart, N. An "electronic fluorescent pictograph" browser for exploring and analyzing large-scale biological data sets. PLOS ONE 2007, 2, doi:10.1371/journal.pone.0000718.

76. Panzeri, D.; Cassani, E.; Doria, E.; Tagliabue, G.; Forti, L.; Campion, B.; Bollini, R.; Brearley, C.A.; Pilu, R.; Nielsen, E.; et al. A defective ABC transporter of the MRP family, responsible for the bean lpal mutation, affects the regulation of the phytic acid pathway, reduces seed myo-inositol and alters aba sensitivity. New Phytol. 2011, 191, 70-83.

77. Gillman, J.; Pantalone, V.; Bilyeu, K. The low phytic acid phenotype in soybean line CX1834 is due to mutations in two homologs of the maize low phytic acid gene. Plant Genome 2009, 2, 179-190.

78. Patel, R.; Nahal, H.; Breit, R.; Provart, N. Bar expressolog identification: Expression profile similarity ranking of homologous genes in plant species. Plant J. 2012, 71, 1038-1050.

79. Pilu, R.; Panzeri, D.; Gavazzi, G.; Rasmussen, S.; Consonni, G.; Nielsen, E. Phenotypic, genetic and molecular characterization of a maize low phytic acid mutant (lpa241). Theor. Appl. Genet. 2003, 107, 980-987.

80. Shukla, S.; VanToai, T.; Pratt, R. Expression and nucleotide sequence of an Ins (3) P-1 synthase gene associated with low-phytate kernels in maize (Zea mays L.). J. Agric. Food Chem. 2004, 52, 4565-4570. 
81. Liu, Q.; Xu, X.; Ren, X.; Fu, H.; Wu, D.; Shu, Q. Generation and characterization of low phytic acid germplasm in rice (Oryza sativa L.). Theor. Appl. Genet. 2007, 114, 803-814.

82. Campion, B.; Sparvoli, F.; Doria, E.; Tagliabue, G.; Galasso, I.; Fileppi, M.; Bollini, R.; Nielsen, E. Isolation and characterisation of an lpa (low phytic acid) mutant in common bean (Phaseolus vulgaris L.). Theor. Appl. Genet. 2009, 118, 1211-1221.

83. Wilcox, J.; Premachandra, G.; Young, K.; Raboy, V. Isolation of high seed inorganic P, low-phytate soybean mutants. Crop Sci. 2000, 40, 1601-1605.

84. Maroof, M.; Glover, N.; Biyashev, R.; Buss, G.; Grabau, E. Genetic basis of the low-phytate trait in the soybean line CX1834. Crop Sci. 2009, 49, 69-76.

85. Gillman, J.; Baxter, I.; Bilyeu, K. Phosphorus partitioning of soybean lines containing different mutant alleles of two soybean seed-specific adenosine triphosphate-binding cassette phytic acid transporter paralogs. Plant Genome 2013, 6, doi:10.3835/plantgenome2012.06.0010.

86. Meis, S.; Fehr, W.; Schnebly, S. Seed source effect on field emergence of soybean lines with reduced phytate and raffinose saccharides. Crop Sci. 2003, 43, 1336-1339.

87. Guttieri, M.; Bowen, D.; Dorsch, J.; Raboy, V.; Souza, E. Identification and characterization of a low phytic acid wheat. Crop Sci. 2004, 44, 418-424.

88. Pilu, R.; Landoni, M.; Cassani, E.; Doria, E.; Nielsen, E. The maize lpa241 mutation causes a remarkable variability of expression and some pleiotropic effects. Crop Sci. 2005, 45, 2096-2105.

89. Bregitzer, P.; Raboy, V. Effects of four independent low-phytate mutations in barley (Hordeum vulgare L.) on seed phosphorus characteristics and malting quality. Cereal Chem. 2006, 83, 460-464.

90. Campion, B.; Glahn, R.; Tava, A.; Perrone, D.; Doria, E.; Sparvoli, F.; Cecotti, R.; Dani, V.; Nielsen, E. Genetic reduction of antinutrients in common bean (Phaseolus vulgaris L.) seed, increases nutrients and in vitro iron bioavailability without depressing main agronomic traits. Field Crop. Res. 2013, 141, 27-37.

91. Ertl, D.; Young, K.; Raboy, V. Plant genetic approaches to phosphorus management in agricultural production. J. Environ. Qual. 1998, 27, 299-304.

92. Bregitzer, P.; Raboy, V. Effects of four independent low-phytate mutations on barley agronomic performance. Crop Sci. 2006, 46, 1318-1322.

93. Raboy, V.; Peterson, K.; Jackson, C.; Marshall, J.; Hu, G.; Saneoka, H.; Bregitzer, P. A substantial fraction of barley (Hordeum vulgare L.) low phytic acid mutations have little or no effect on yield across diverse production environments. Plants 2015, 4, 225-239.

94. Bregitzer, P.; Raboy, V.; Obert, D.; Windes, J.; Whitmore, J. Registration of "Herald" barley. Crop Sci. 2007, 47, 441-442.

95. Bregitzer, P.; Raboy, V.; Obert, D.; Windes, J.; Whitmore, J. Registration of “Clearwater" low-phytate hulless spring barley. J. Plant Regist. 2008, 2, 1-4.

96. Valluru, R.; van den Ende, W. Myo-inositol and beyond-Emerging networks under stress. Plant Sci. 2011, 181, 387-400.

97. Gillaspy, G. The cellular language of myo-inositol signaling. New Phytol. 2011, 192, 823-839.

98. Dieck, C.; Boss, W.; Perera, I. A role for phosphoinositides in regulating plant nuclear functions. Front. Plant Sci. 2012, 3, doi:10.3389/fpls.2012.00050. 
99. Gillaspy, G.E. The role of phosphoinositides and inositol phosphates in plant cell signaling. In Lipid-Mediated Protein Signaling; Capelluto, D., Ed.; Springer: Dordrecht, The Netherlands, 2013; Volume 991, pp. 141-157.

100. Heilmann, M.; Heilmann, I. Plant phosphoinositides-complex networks controlling growth and adaption. Biochim. Biophys. Acta 2015, 1851, 759-769.

101. Yuan, F.; Zhu, D.; Deng, B.; Fu, X.; Dong, D.; Zhu, S.; Li, B.; Shu, Q. Effects of two low phytic acid mutations on seed quality and nutritional traits in soybean (Glycine max L. Merr). J. Agric. Food Chem. 2009, 57, 3632-3638.

102. Meng, P.; Raynaud, C.; Tcherkez, G.; Blanchet, S.; Massoud, K.; Domenichini, S.; Henry, Y.; Soubigou-Taconnat, L.; Lelarge-Trouverie, C.; Saindrenan, P.; et al. Crosstalks between myo-inositol metabolism, programmed cell death and basal immunity in Arabidopsis. PLoS ONE 2009, 4, doi:10.1371/journal.pone.0007364.

103. Chen, H.; Xiong, L. Myo-inositol-1-phosphate synthase is required for polar auxin transport and organ development. J. Biol. Chem. 2010, 285, 24238-24247.

104. Liu, J.; Ockenden, I.; Truax, M.; Lott, J. Phytic acid-phosphorus and other nutritionally important mineral nutrient elements in grains of wild-type and low phytic acid (lpa1-1) rice. Seed Sci. Res. 2004, 14, 109-116.

105. Cerino Badone, F.; Amelotti, M.; Cassani, E.; Pilu, R. Study of low phytic acid1-7 (lpa1-7), a new ZmMRP4 mutation in maize. J. Hered. 2012, 103, 598-605.

106. Doria, E.; Galleschi, L.; Calucci, L.; Pinzino, C.; Pilu, R.; Cassani, E.; Nielsen, E. Phytic acid prevents oxidative stress in seeds: Evidence from a maize (Zea mays L.) low phytic acid mutant. J. Exp. Bot. 2009, 60, 967-978.

107. Karner, U.; Peterbauer, T.; Raboy, V.; Jones, D.; Hedley, C.; Richter, A. Myo-inositol and sucrose concentrations affect the accumulation of raffinose family oligosaccharides in seeds. J. Exp. Bot. 2004, 55, 1981-1987.

108. Frank, T.; Meuleye, B.; Miller, A.; Shu, Q.; Engel, K. Metabolite profiling of two low phytic acid (lpa) rice mutants. J. Agric. Food Chem. 2007, 55, 11011-11019.

109. Dong, J.; Yan, W.; Bock, C.; Nokhrina, K.; Keller, W.; Georges, F. Perturbing the metabolic dynamics of myo-inositol in developing brassica napus seeds through in vivo methylation impacts its utilization as phytate precursor and affects downstream metabolic pathways. BMC Plant Biol. 2013, 13, 84, doi:10.1186/1471-2229-13-84.

110. Keller, R.; Brearley, C.; Trethewey, R.; Muller-Rober, B. Reduced inositol content and altered morphology in transgenic potato plants inhibited for 1D-myo-inositol 3-phosphate synthase. Plant J. 1998, 16, 403-410.

111. Donahue, J.; Alford, S.; Torabinejad, J.; Kerwin, R.; Nourbakhsh, A.; Ray, W.; Hernick, M.; Huang, X.; Lyons, B.; Hein, P.; et al. The Arabidopsis thaliana myo-inositol 1-phosphate synthase1 gene is required for myo-inositol synthesis and suppression of cell death. Plant Cell 2010, 22, 888-903.

112. Burnette, R.; Gunesekera, B.; Gillaspy, G. An Arabidopsis inositol 5-phosphatase gain-of-function alters abscisic acid signaling. Plant Physiol. 2003, 132, 1011-1019.

113. Gunesekera, B.; Torabinejad, J.; Robinson, J.; Gillaspy, G. Inositol polyphosphate 5-phosphatases 1 and 2 are required for regulating seedling growth. Plant Physiol. 2007, 143, 1408-1417. 
114. Xiong, L.; Lee, B.H.; Ishitani, M.; Lee, H.; Zhang, C.; Zhu, J.K. FIERY1 encoding an inositol polyphosphate 1-phosphatase is a negative regulator of abscisic acid and stress signaling in Arabidopsis. Genes Dev. 2001, 15, 1971-1984.

115. Ananieva, E.A.; Gillaspy, G.E. Switches in nutrient and inositol signaling. Plant Signal. Behav. 2009, 4, 304-306.

116. Loewus, F.A. Inositol and plant cell wall polysaccharide biogenesis. Subcell. Biochem. 2006, 39, 21-45.

117. Lorence, A.; Chevone, B.I.; Mendes, P.; Nessler, C.L. Myo-inositol oxygenase offers a possible entry point into plant ascorbate biosynthesis. Plant Physiol. 2004, 134, 1200-1205.

118. Lemtiri-Chlieh, F.; MacRobbie, E.; Webb, A.; Manison, N.; Brownlee, C.; Skepper, J.; Chen, J.; Prestwich, G.; Brearley, C. Inositol hexakisphosphate mobilizes an endomembrane store of calcium in guard cells. Proc. Natl. Acad. Sci. USA 2003, 100, 10091-10095.

119. Sztein, A.; Cohen, J.; Cooke, T. Evolutionary patterns in the auxin metabolism of green plants. Int. J. Plant Sci. 2000, 161, 849-859.

120. Thole, J.; Nielsen, E. Phosphoinositides in plants: Novel functions in membrane trafficking. Curr.Opin. Plant Biol. 2008, 11, 620-631.

121. Munnik, T.; Vermeer, J. Osmotic stress-induced phosphoinositide and inositol phosphate signalling in plants. Plant Cell Environ. 2010, 33, 655-669.

122. Kuo, H.; Chang, T.; Chiang, S.; Wang, W.; Charng, Y.; Chiou, T. Arabidopsis inositol pentakisphosphate 2-kinase, AtIPK1, is required for growth and modulates phosphate homeostasis at the transcriptional level. Plant J. 2014, 80, 503-515.

123. Latrasse, D.; Jegu, T.; Meng, P.; Mazubert, C.; Hudik, E.; Delarue, M.; Charon, C.; Crespi, M.; Hirt, H.; Raynaud, C.; et al. Dual function of MIPS1 as a metabolic enzyme and transcriptional regulator. Nucl. Acids Res. 2013, 41, 2907-2917.

124. Lee, H.; Lee, D.; Cho, H.; Kim, S.; Auh, J.; Pai, H. InsP6-sensitive variants of the Gle1 mRNA export factor rescue growth and fertility defects of the ipk1 low-phytic-acid mutation in Arabidopsis. Plant Cell 2015, 27, 417-431.

125. Lemtiri-Chlieh, F.; MacRobbie, E.; Brearley, C. Inositol hexakisphosphate is a physiological signal regulating the $\mathrm{K}^{+}$-inward rectifying conductance in guard cells. Proc. Natl. Acad. Sci. USA 2000, 97, 8687-8692.

126. Tan, X.; Calderon-Villalobos, L.I.; Sharon, M.; Zheng, C.; Robinson, C.V.; Estelle, M.; Zheng, N. Mechanism of auxin perception by the tir1 ubiquitin ligase. Nature 2007, 446, 640-645.

127. Laha, D.; Johnen, P.; Azevedo, C.; Dynowski, M.; Weiss, M.; Capolicchio, S.; Mao, H.; Iven, T.; Steenbergen, M.; Freyer, M.; et al. VIH2 regulates the synthesis of inositol pyrophosphate InsP 8 and jasmonate-dependent defenses in Arabidopsis. Plant Cell 2015, 27, 1082-1097.

128. Fassetti, F.; Leone, O.; Palopoli, L.; Rombo, S.E.; Saiardi, A. IP6K gene identification in plant genomes by tag searching. BMC Proc. 2011, 5, doi:10.1186/1753-6561-5-S2-S1.

129. Desai, M.; Rangarajan, P.; Donahue, J.; Williams, S.; Land, E.; Mandal, M.; Phillippy, B.; Perera, I.; Raboy, V.; Gillaspy, G. Two inositol hexakisphosphate kinases drive inositol pyrophosphate synthesis in plants. Plant J. 2014, 80, 642-653.

130. Shears, S.B. Inositol pyrophosphates: Why so many phosphates? Adv. Biol. Regul. 2015, 57, 203-216. 
131. Williams, M.; Torabinejad, J.; Cohick, E.; Parker, K.; Drake, E.; Thompson, J.; Hortter, M.; DeWald, D. Mutations in the Arabidopsis phosphoinositide phosphatase gene SAC9 lead to overaccumulation of Ptdins $(4,5) \mathrm{P}_{2}$ and constitutive expression of the stress-response pathway. Plant Physiol. 2005, 138, 686-700.

132. Perera, I.; Hung, C.; Moore, C.; Stevenson-Paulik, J.; Boss, W. Transgenic Arabidopsis plants expressing the type 1 inositol 5-phosphatase exhibit increased drought tolerance and altered abscisic acid signaling. Plant Cell 2008, 20, 2876-2893.

133. Im, Y.; Perera, I.; Brglez, I.; Davis, A.; Stevenson-Paulik, J.; Phillippy, B.; Johannes, E.; Allen, N.; Boss, W. Increasing plasma membrane phosphatidylinositol(4,5)bisphosphate biosynthesis increases phosphoinositide metabolism in nicotiana tabacum. Plant Cell 2007, 19, 1603-1616.

134. Perera, I.; Love, J.; Heilmann, I.; Thompson, W.; Boss, W. Up-regulation of phosphoinositide metabolism in tobacco cells constitutively expressing the human type i inositol polyphosphate 5-phosphatase. Plant Physiol. 2002, 129, 1795-1806.

135. Perera, I.; Hung, C.; Brady, S.; Muday, G.; Boss, W. A universal role for inositol 1,4,5-trisphosphate-mediated signaling in plant gravitropism. Plant Physiol. 2006, 140, 746-760.

136. Ananieva, E.; Gillaspy, G.; Ely, A.; Burnette, R.; Erickson, F. Interaction of the WD40 domain of a myoinositol polyphosphate 5-phosphatase with SnRK1 links inositol, sugar, and stress signaling. Plant Physiol. 2008, 148, 1868-1882.

137. Baena-Gonzalez, E.; Sheen, J. Convergent energy and stress signaling. Trends Plant Sci. 2008, 13, 474-482.

138. Chen, X.; Lin, W.; Wang, Y.; Luan, S.; Xue, H. An inositol polyphosphate 5-phosphatase functions in phototropin 1 signaling in arabidopis by altering cytosolic $\mathrm{Ca}^{2+}$. Plant Cell 2008, 20, 353-366.

139. Wang, W.; Yang, X.; Tangchaiburana, S.; Ndeh, R.; Markham, J.; Tsegaye, Y.; Dunn, T.; Wang, G.; Bellizzi, M.; Parsons, J.; et al. An inositolphosphorylceramide synthase is involved in regulation of plant programmed cell death associated with defense in Arabidopsis. Plant Cell 2008, 20, 3163-3179.

140. Zhang, J.; Vanneste, S.; Brewer, P.; Michniewicz, M.; Grones, P.; Kleine-Vehn, J.; Lofke, C.; Teichmann, T.; Bielach, A.; Cannoot, B.; et al. Inositol trisphosphate-induced $\mathrm{Ca}^{2+}$ signaling modulates auxin transport and pin polarity. Dev. Cell 2011, 20, 855-866.

141. Bruggeman, Q.; Prunier, F.; Mazubert, C.; de Bont, L.; Garmier, M.; Lugan, R.; Benhamed, M.; Bergounioux, C.; Raynaud, C.; Delarue, M. Involvement of Arabidopsis hexokinase1 in cell death mediated by myo-inositol accumulation.Plant Cell 2015, 27, 1801-1814.

142. Hung, C.; Aspesi, P.; Hunter, M.; Lomax, A.; Perera, I. Phosphoinositide-signaling is one component of a robust plant defense response. Front. Plant Sci. 2014, 5, doi:10.3389/fpls.2014.00267.

143. Mosblech, A.; Thurow, C.; Gatz, C.; Feussner, I.; Heilmann, I. Jasmonic acid perception by coi1 involves inositol polyphosphates in Arabidopsis thaliana. Plant J. 2011, 65, 949-957.

144. Zhai, H.; Wang, F.; Si, Z.; Huo, J.; Xing, L.; An, Y.; He, S.; Liu, Q. A myo-inositol-1-phosphate synthase gene, IbMIPS1, enhances salt and drought tolerance and stem nematode resistance in transgenic sweet potato. Plant Biotechnol. J. 2015, doi:10.1111/pbi.12402.

145. Alcazar-Roman, A.; Wente, S. Inositol polyphosphates: A new frontier for regulating gene expression. Chromosoma 2008, 117, 1-13. 
146. Xia, H.; Brearley, C.; Elge, S.; Kaplan, B.; Fromm, H.; Mueller-Roeber, B. Arabidopsis inositol polyphosphate 6-/3-kinase is a nuclear protein that complements a yeast mutant lacking a functional ArgR-Mcm1 transcription complex. Plant Cell 2003, 15, 449-463.

147. Monserrate, J.; York, J. Inositol phosphate synthesis and the nuclear processes they affect. Curr. Opin. Cell Biol. 2010, 22, 365-373.

148. Shen, X.; Xiao, H.; Ranallo, R.; Wu, W.; Wu, C. Modulation of ATP-dependent chromatin-remodeling complexes by inositol polyphosphates. Science 2003, 299, 112-114.

149. Saiardi, A.; Caffrey, J.; Snyder, S.; Shears, S. Inositol polyphosphate multikinase (ArgRIII) determines nuclear mRNA export in Saccharomyces cerevisiae. FEBS Lett. 2000, 468, 28-32.

150. Steger, D.; Haswell, E.; Miller, A.; Wente, S.; O’Shea, E. Regulation of chromatin remodeling by inositol polyphosphates. Science 2003, 299, 114-116.

151. Zhang, Z.; Liao, H.; Lucas, W. Molecular mechanisms underlying phosphate sensing, signaling, and adaptation in plants. J. Integr. Plant Biol. 2014, 56, 192-220.

152. Belgaroui, N.; Zaidi, I.; Farhat, A.; Chouayekh, H.; Bouain, N.; Chay, S.; Curie, C.; Mari, S.; Masmoudi, K.; Davidian, J.; et al. Over-expression of the bacterial phytase US417 in Arabidopsis reduces the concentration of phytic acid and reveals its involvement in the regulation of sulfate and phosphate homeostasis and signaling. Plant Cell Physiol. 2014, 55, 1912-1924.

153. Sheard, L.; Tan, X.; Mao, H.; Withers, J.; Ben-Nissan, G.; Hinds, T.; Kobayashi, Y.; Hsu, F.; Sharon, M.; Browse, J.; et al. Jasmonate perception by inositol-phosphate-potentiated COI1-JAZ co-receptor. Nature 2010, 468, U400-U301.

154. Santner, A.; Estelle, M. Recent advances and emerging trends in plant hormone signalling. Nature 2009, 459, 1071-1078.

(C) 2015 by the authors; licensee MDPI, Basel, Switzerland. This article is an open access article distributed under the terms and conditions of the Creative Commons Attribution license (http://creativecommons.org/licenses/by/4.0/). 